\title{
Review of the Magnetocaloric Effect in $\mathrm{RMnO}_{3}$ and $\mathrm{RMn}_{2} \mathrm{O}_{5}$ Multiferroic Crystals
}

\author{
Mohamed Balli 1,2, ${ }^{\text {, Benoit Roberge }}{ }^{1,2}$, Patrick Fournier 1,2,3 and Serge Jandl 1,2 \\ 1 Institut Quantique, Université de Sherbrooke, Sherbrooke, QC J1K 2R1, Canada; \\ benoit.roberge@usherbrooke.ca (B.R.); patrick.fournier@usherbrooke.ca (P.F.); \\ serge.jandl@usherbrooke.ca (S.J.) \\ 2 Regroupement Québécois sur les Matériaux de Pointe, Département de Physique, Université de Sherbrooke, \\ QC J1K 2R1, Canada \\ 3 Canadian Institute for Advanced Research, Toronto, ON M5G 1Z8, Canada \\ * Correspondence: Mohamed.balli@usherbrooke.ca
}

Academic Editor: Iwan Kityk

Received: 23 December 2016; Accepted: 4 February 2017; Published: 8 February 2017

\begin{abstract}
It is known that some of $\mathrm{RMnO}_{3}$ and $\mathrm{RMn}_{2} \mathrm{O}_{5}(\mathrm{R}=$ rare earth) multiferroic crystals reveal a strong interplay between their magnetic and electric order parameters, paving the way for applications in spintronic technologies. Additionally, recent works have also pointed out their potential utilization as refrigerants in magnetocaloric cooling systems for cryogenic tasks. In this paper, recent advances regarding the magnetocaloric properties of both $\mathrm{RMnO}_{3}$ and $\mathrm{RMn}_{2} \mathrm{O}_{5}$ families of multiferroics are reviewed. With the aim of understanding the $\mathrm{RMnO}_{3}$ and $\mathrm{RMn}_{2} \mathrm{O}_{5}$ magnetocaloric features, their structural and magnetic properties are discussed. The physics behind the magnetocaloric effect as well as some of its key thermodynamic aspects are also considered.
\end{abstract}

Keywords: $\mathrm{RMnO}_{3} ; \mathrm{RMn}_{2} \mathrm{O}_{5}$; multiferroics; anisotropy; single crystals; magnetocaloric effect; magnetic cooling

\section{Introduction}

In recent years great attention has been paid to the development of new functional materials with potential applications in more efficient and clean technologies. In this context, magnetocaloric materials have generated a worldwide interest due to their potential utilization as solid-state refrigerants in magnetic cooling devices [1-14]. Based on the well-known magnetocaloric effect (MCE), the magnetic refrigeration technique would enable the harmful synthetic refrigerants usually present in the conventional refrigerators to be completely phased out while offering a high thermodynamic efficiency [15-17]. The search for optimum magnetocaloric materials is then a key parameter in the development of magnetic cooling systems. For room temperature tasks, rare-earth elements-based alloys [14] and particularly the gadolinium metal have been widely used as refrigerants and successfully implemented in functional devices [15-17]. However, their high cost and their poor resistance to corrosion and oxidation strictly limit their utilization in large scale applications of magnetocaloric refrigeration. For this purpose, worldwide intensive researches have been conducted leading to the discovery of new "cheaper and efficient" magnetocaloric materials including both transition elements and intermetallic-based compounds such as $\mathrm{Fe}_{2} \mathrm{P}$ type materials (MnFePAs) $[6,7]$ and $\mathrm{LaFe}_{13-\mathrm{x}} \mathrm{Si}_{\mathrm{x}}$ compounds [8-13]. Most of these materials exhibit a first order magnetic phase transition close to room temperature which explains their large magnetocaloric effect, particularly in terms of the entropy change. On the other hand, much attention has also been paid to materials that present good magnetocaloric properties in the cryogenic temperature range due to their 
potential implementation in numerous applications such as scientific facilities, space technologies, and gas liquefaction.

It is worth noting that the rising cost of helium opens the way for the development of new alternatives to conventional liquid-helium refrigerators. In addition, as claimed by Barclay et al. [18], a large scale utilization of hydrogen as a source of energy will result in better energy security with major environmental, economic, and social benefits. In this context, several cryomagnetocaloric materials have been proposed [19-28]. Following this, Matsumoto et al. [29,30] unveiled a reciprocating magnetic refrigerator dedicated to hydrogen liquefaction that uses the $\mathrm{Dy}_{2.4} \mathrm{Gd}_{0.6} \mathrm{Al}_{5} \mathrm{O}_{12}$ garnet as refrigerant.

The multiferroic crystals $\mathrm{RMn}_{2} \mathrm{O}_{5}$ [31-36] and $\mathrm{RMnO}_{3}(\mathrm{R}=$ rare earth) [37-41] have been extensively explored due to their fascinating physical properties as well as potential applications in spintronic devices. Especially, some of these systems show a strong coupling between magnetism and ferroelectricity which provides an additional degree of freedom regarding the design of magnetoelectric effect-based machines [30-40]. On the other hand, the investigation of their magnetocaloric properties has unveiled a great potential for application in magnetic refrigeration at low temperature regime [19-28]. This means that more than one task can be achieved by only using a single $\mathrm{RMn}_{2} \mathrm{O}_{5}$ or $\mathrm{RMnO}_{3}$ material which is of great interest from an economical point of view.

Although several intermetallic materials with excellent magnetocaloric properties such as $\mathrm{RAl}_{2}$ [42] have been proposed for low temperature application, the chemical and mechanical instabilities remain serious obstacles to their utilization. For example, one of the major problems with these materials is that they experience decomposition due to hydrogen absorption [30]. In addition, the implementation of intermetallics as refrigerants in functional devices, favors the creation of an eddy current during the magnetization-demagnetization process, leading to undesirable thermal losses [43]. These drawbacks could be avoided by using $\mathrm{RMn}_{2} \mathrm{O}_{5}$ or $\mathrm{RMnO}_{3}$ oxides which reveal an insulating character combined with high chemical and mechanical stabilities [12].

It is also worth noting that in addition to a large conventional MCE that can be generated by varying the magnitude of external magnetic field, some of the $\mathrm{RMn}_{2} \mathrm{O}_{5}$ and $\mathrm{RMnO}_{3}$ crystals exhibit a giant thermal effect when they are rotated around their intermediate axis in constant magnetic fields [19-21]. This rotating MCE resulting from the large magnetic anisotropy shown by these crystals would enable more efficient and compact cryomagnetocaloric refrigerators with simplified designs to be built $[19,20]$. In this paper, we particularly discuss the recent developments in relation with the magnetocaloric properties of $\mathrm{RMn}_{2} \mathrm{O}_{5}$ and $\mathrm{RMnO}_{3}$ crystals. In order to understand their magnetoelectric and magnetocaloric properties, some theoretical background is also given.

\section{Magnetocaloric Effect: Theoretical Aspects}

Nowadays, magnetic cooling systems are based on the conventional magnetocaloric effect, an intrinsic property that can be defined as the thermal response of certain magnetic materials when subjected to a variable external magnetic field. This effect manifests itself as a temperature change resulting from the magnetic entropy variation because of the magneto-thermal coupling between phonons and magnetic moment sublattices. In fact, the full entropy of a magnetic substance in the presence of an external magnetic field $H\left(B=\mu_{0} H\right)$ can usually be expressed as follows:

$$
S(T, H)=S_{L a t}(T, H)+S_{E l}(T, H)+S_{m}(T, H)
$$

where $S_{L a t}, S_{E l}$, and $S_{m}$ are the lattice, electronic and magnetic entropies, respectively. In a magnetic field, the magnetic moments change their ordering state, increasing (or decreasing) consequently the system's magnetic entropy. In adiabatic conditions, the conservation of the full entropy involves the evolution of the lattice contribution in the opposite way, raising then (or lowering) the magnetic material's temperature. For ferromagnets and paramagnets (Figure 1), the application of an external magnetic field tends to render the magnetic spins more ordered and correspondingly the magnetic entropy is decreased. The magnetic substance compensates for this loss by heating up (atoms 
vibrate more). When the magnetic field is reduced to zero, the magnetic moments randomize again, the magnetic entropy increases, the lattice part decreases and the magnetic material is cooled down. However, in the case of antiferromagnetic materials, the application of an external magnetic field usually transforms the magnetic phase from an ordered to a less-ordered state giving rise to a negative (or inverse) magnetocaloric effect [44].

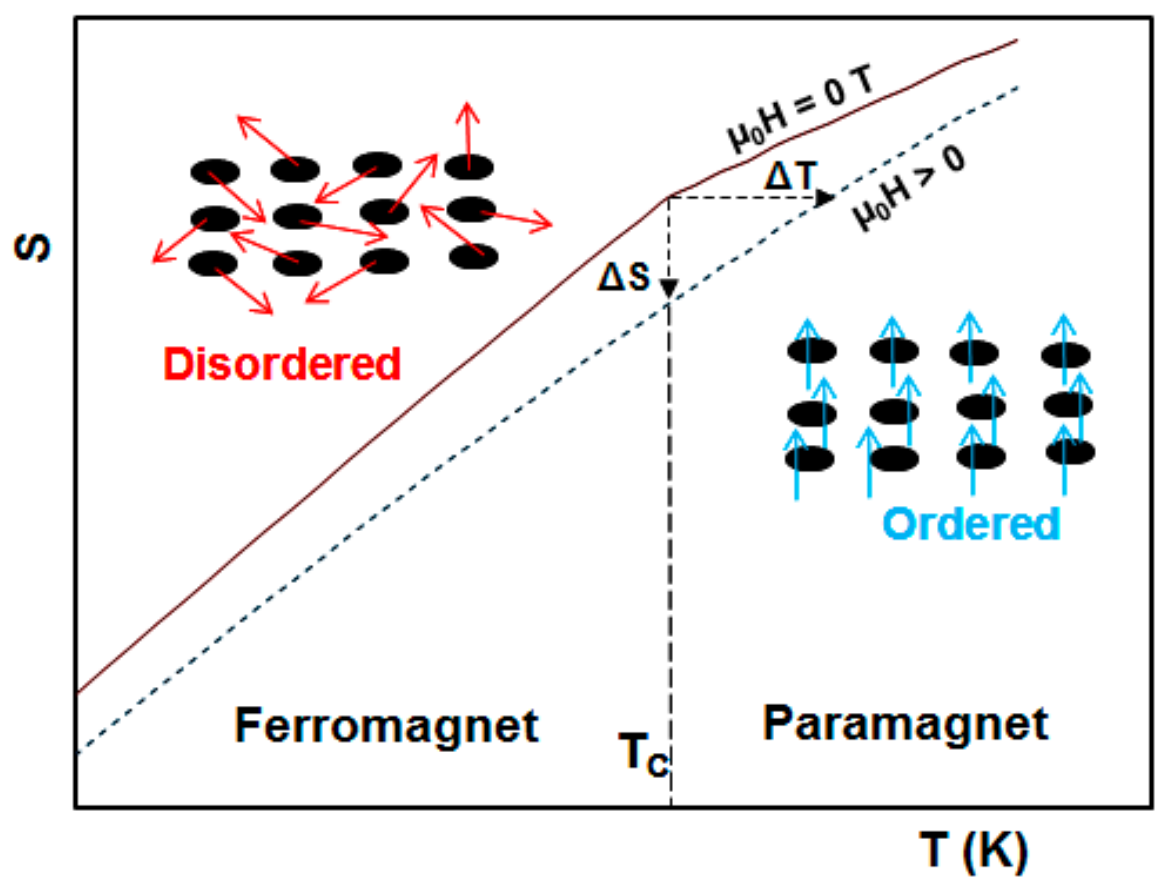

Figure 1. Principle of the conventional magnetocaloric effect (MCE).

The MCE is mainly characterized by the adiabatic temperature change $\Delta T_{a d}$ and the isothermal entropy change $\Delta S$. Both thermodynamic quantities are shown in Figure 1 for an initial temperature $T_{C}$ (Curie point) and a magnetic field changing from 0 to $\mathrm{H}$. $\Delta T_{a d}$ can be directly measured by a system of thermocouples or indirectly deduced from specific heat measurements as a function of temperature and magnetic field using the following equation [42]:

$$
S(T, B)=\int_{0}^{T} \frac{C_{P}\left(T^{\prime}, B\right)}{T^{\prime}} d T^{\prime}
$$

$\Delta T_{a d}$ can then be determined from $S(T, B)$ curves as shown in Figure 1. However, due to the complexity of calorimetric measurements, the MCE is usually reported in terms of $\Delta S$ that can be determined from isothermal magnetization curves with the help of the Maxwell equation. This latter is given by:

$$
\Delta S(T, 0 \rightarrow B)=\int_{0}^{B}\left(\frac{\partial M}{\partial T}\right)_{P, B} d B^{\prime}
$$

Since the magnetization data are usually collected at discrete values of magnetic field and temperature, $\Delta S$ can be approached by the following numerical form:

$$
\Delta S=\sum_{i} \frac{M_{i+1}-M_{i}}{T_{i+1}-T_{i}} \Delta B_{i}
$$

where $M_{i+1}$ and $M_{i}$ are the magnetizations corresponding to $T_{i+1}$ and $T_{i}$, respectively, in a magnetic field $B$. However, this technique must be used carefully [45,46], particularly in the case of first order 
magnetic phase transition (FOMT) materials that show a large hysteresis effect (out of equilibrium). In some metamagnetic materials $[45,46]$ the hysteresis effect results in phase-separated states. However, under the effect of an external magnetic field, the MCE is mainly contributed from only one magnetic phase which is not taken into account when directly integrating the Maxwell relation $[45,46]$. The MCE associated with metamagnetic regions can well be estimated from the Clausius-Clapeyron equation that directly links the entropy change to the magnetization jump [45,46]. It is given by

$$
\Delta S=-\Delta M \frac{d B_{C}}{d T}=-\Delta M\left(\frac{d T_{T}}{d B}\right)^{-1}
$$

where $B_{C}$ and $T_{r}$ are the critical magnetic field and the transition temperature, respectively.

As outlined in Section 1, thermal effects can also be induced by rotating some single crystals that show a large anisotropy between their easy and hard-axes (Figure 2) in constant magnetic fields $[19,20]$. As shown in Figure 2b, such an effect could open the way for the design of new types of magnetic refrigerators. Similarly to the standard MCE, the rotating MCE is also represented by adiabatic $\left(\Delta T_{a d, R}\right)$ and entropy $\left(\Delta S_{R}\right)$ changes. Both parameters can be obtained from specific heat measurements by building full entropy curves along the hard and easy-axes (Figure 2a). Considering the magnetic field initially parallel to the hard-axis, the entropy change resulting from the rotation of a single crystal around its intermediate axis by an angle of $90^{\circ}$ can be written as

$$
\Delta S_{R, h e}=\Delta S(H / / e)-\Delta S(H / / h)
$$

where $\Delta S(H / / e)$ and $\Delta S(H / / h)$ are the entropy changes corresponding to the application of a magnetic field along the easy and hard-directions, respectively. This means that the rotating entropy change can also be evaluated from magnetization data using the Maxwell equation [19-21].
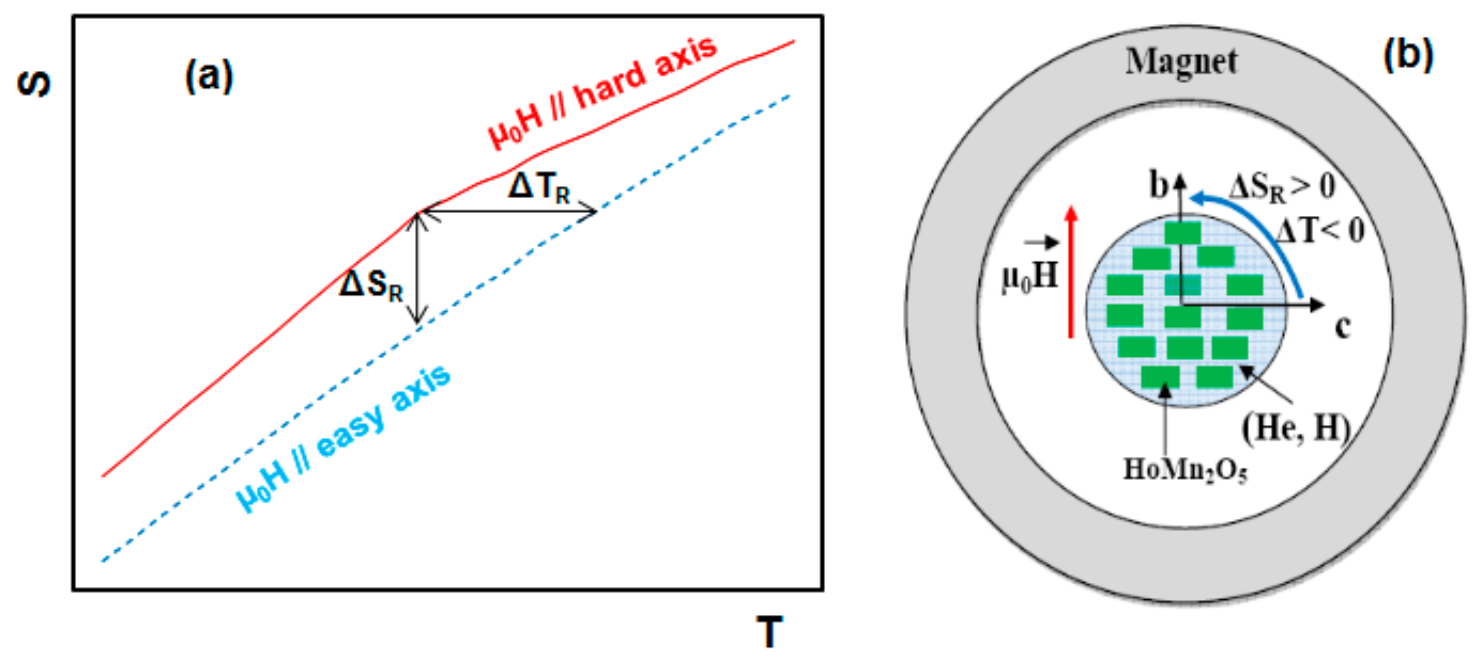

Figure 2. (a) Principle of the rotating magnetocaloric effect. (b) Generation of the magnetocaloric effect by rotating $\mathrm{HoMn}_{2} \mathrm{O}_{5}$ single crystals between their easy (b-axis) and hard (c-axis) axes [19]. Helium and hydrogen gas can be then liquefied by using them as heat transfer fluids [19].

The refrigerant capacity is another figure of merit for the characterization of magnetocaloric materials [47]. This parameter, not only takes into account the magnitude of the MCE but also the operating temperature range. It is given by:

$$
R C=\int_{T_{C}}^{T_{H}} \Delta S(T) d T
$$


With $T_{H}$ and $T_{C}$ the cold and hot temperatures correspond to the half maximum of the $\Delta S$ as a function of temperature. More recently, $R C$ was found to linearly scale with the exergetic cooling power of an AMR thermodynamic cycle [48].

\section{Brief Description of the Magnetoelectric Interplay in $\mathrm{RMnO}_{3}$ and $\mathrm{RMn}_{2} \mathrm{O}_{5}$ Multiferroics}

It is known that the ferroelectricity in hexagonal $\mathrm{RMnO}_{3}$ multiferroics mainly arises from structural distortions involving an asymmetric coordination of oxygen atoms around the rare earth ion [49]. In orthorhombic $\mathrm{RMnO}_{3}(\mathrm{R}=\mathrm{Gd}, \mathrm{Tb}$ and $\mathrm{Dy})$ and $\mathrm{RMn}_{2} \mathrm{O}_{5}$ systems, the ferroelectric order emerges from a frustrated magnetic order leading to a strong magnetoelectric coupling [50-60]. For these compounds the magnetic frustration originates from two different scenarios: the first one involves the competition between different magnetic exchange interactions while the second one arises from the incompatibility between the lattice geometry and the magnetic interaction ruling the spins configuration [33,37]. Due to the orbital ordering of $\mathrm{Mn}^{3+}$ ions in orthorhombic $\mathrm{RMnO}_{3}$, the exchange interactions favor a ferromagnetic (FM) configuration in the ab-planes and an antiferromagnetic arrangement (AFM) along the c-axis. Such order is observed in large $\mathrm{R}$-radii $\mathrm{RMnO}_{3}(\mathrm{R}=\mathrm{La}, \mathrm{Pr}$, $\mathrm{Nd}, \mathrm{Sm}$, and $\mathrm{Eu})[53,54]$. However, the decrease of the R-radii $(\mathrm{R}=\mathrm{Dy}, \mathrm{Tb}$, and $\mathrm{Gd})$ increases both the $\mathrm{GdFeO}_{3}$-type lattice distortion and the octahedra tilting (see Figure 3). In these much-distorted systems, the competition between different magnetic exchange interactions is embedded and the spin structure becomes sinusoidally modulated in the ab-plane below 39-43 K and spirally modulated below 18-27 K [37]. On the contrary, all $\mathrm{RMn}_{2} \mathrm{O}_{5}(\mathrm{R}=$ rare-earth, $\mathrm{Y}$ and $\mathrm{Bi})$, except $\mathrm{PrMn}_{2} \mathrm{O}_{5}$, are multiferroic compounds [61]. For these systems, the ferroelectricity is induced by a collinear magnetic order. It is particularly observed when a commensurate magnetic $(\mathrm{CM})$ phase appears. To explain the microscopic mechanism of the ferroelectricity in the non-collinear magnets $\mathrm{RMnO}_{3}$, Kastura et al. [55], suggested a pure electronic model. This latter suggests that the electronic polarization, induced by two adjacent magnetic moments $\vec{S}_{i}$ and $\vec{S}_{j}$ is given by $\vec{P} \propto \vec{e}_{i j} \times\left(\vec{S}_{i} \times \vec{S}_{j}\right)$ where $\vec{e}_{i j}$ is the unit vector connecting the sites $i$ and $j$. This model presumed that the ions are not displaced from their centrosymmetric positions. In contrast, Sergienko et al. [56] concluded that the oxygen ion displacements are essential for the ferroelectric polarization in these non-collinear magnets. This last model suggested that the ferroelectricity is rather induced by the antisymmetric Dzyaloshinskii-Moriya interaction $\vec{D}_{n, n+1} \propto \vec{S}_{n} \times \vec{S}_{n+1}$. The system can stabilize its magnetic structure by pushing the oxygen further away from the two $\mathrm{Mn}^{3+}$ ions. Because of the spiral order symmetry, the exchange striction will move the oxygens along one direction perpendicular to the spiral direction breaking the inversion symmetry as shown in Figure 4 [56]. Other sophisticated mechanisms have suggested combined contributions [62]. The ferroelectricity in $\mathrm{RMn}_{2} \mathrm{O}_{5}$ is often connected to a symmetric Mn-Mn exchange interaction $[33,63]$.

Phenomenologically, the coupling mechanism between the electric polarization $\mathrm{P}$ and the magnetization $M$ can be explained in the framework of Landau theory. The order parameter $P$ changes its sign under the inversion of all the coordinates, $\mathbf{r} \rightarrow-\mathbf{r}$, but remains invariant on time reversal, $\mathrm{t} \rightarrow-\mathrm{t}$. On the other hand, $M$ transforms into the opposite way and changes its sign under time reversal while remaining invariant under spatial inversion. These symmetry considerations forbid any direct linear coupling mechanisms (P.M). For magnetic systems with non-collinear spin configurations, magnetoelectric coupling can be described with the spatial derivative term $\propto \vec{P} \cdot[\vec{M}(\nabla \cdot \vec{M})-(\vec{M} \cdot \nabla) \vec{M}+\ldots]$. For example, in a cubic crystal [50-52], such coupling could result in a net electric polarization moment $\vec{P} \propto[\vec{M}(\nabla \cdot \vec{M})-(\vec{M} \cdot \nabla) \vec{M}]$. This expression confirms that only a spiral magnetic order $M=M_{1} e_{1} \cos Q . r+M_{2} e_{2} \sin Q . r+M_{3} e_{3}$ can induce a ferroelectric order with a polarization $P$ proportional to $\propto-M_{1} \cdot M_{2} \cdot\left[e_{3} \wedge Q\right]$ where $Q$ is the wave vector propagation. For collinear magnets, Oh et al. [64] successfully explained the magnetoelectric phenomena in $\mathrm{TbMn}_{2} \mathrm{O}_{5}$ using a fourth order $(P . M)^{2}$ coupling term. 


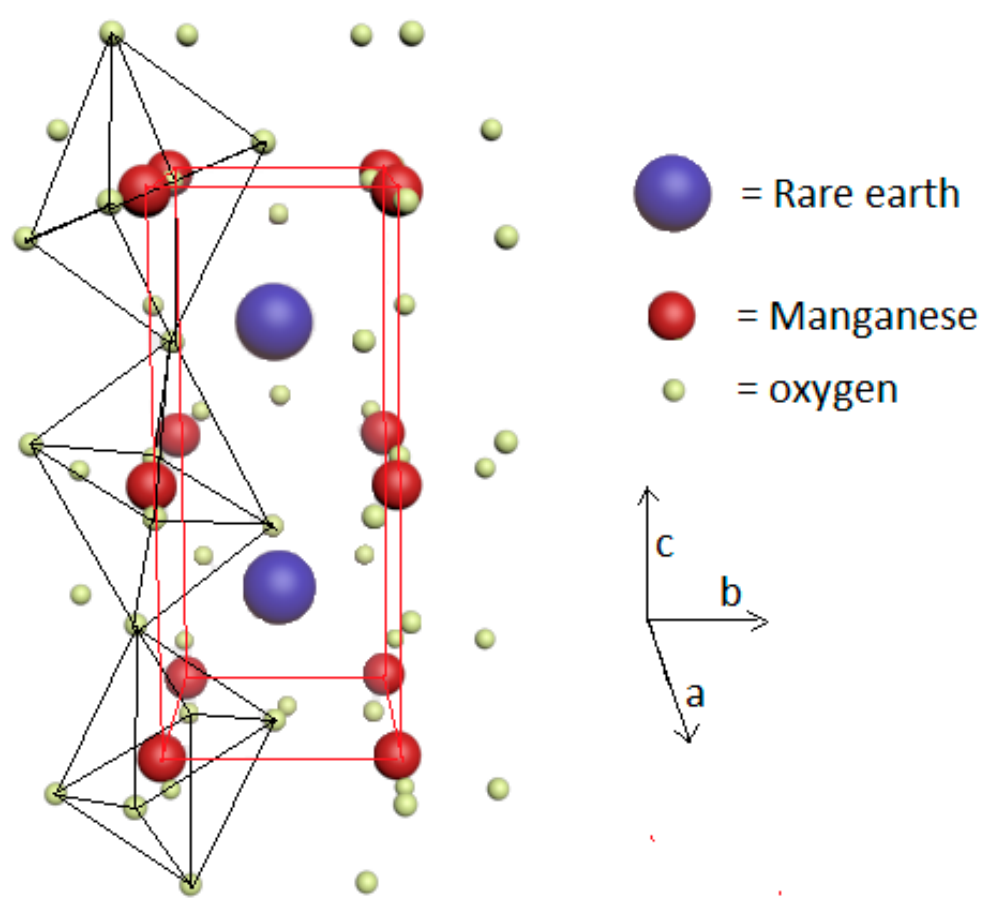

Figure 3. Perovskite orthorhombic structure of $\mathrm{RMnO}_{3}$. Smaller $\mathrm{R}^{3+}$ radii will increase the oxygens's octaedra tilting and ultimately will influence the super-exchange interaction mediating the ordering of $\mathrm{Mn}^{3+}$ spins.

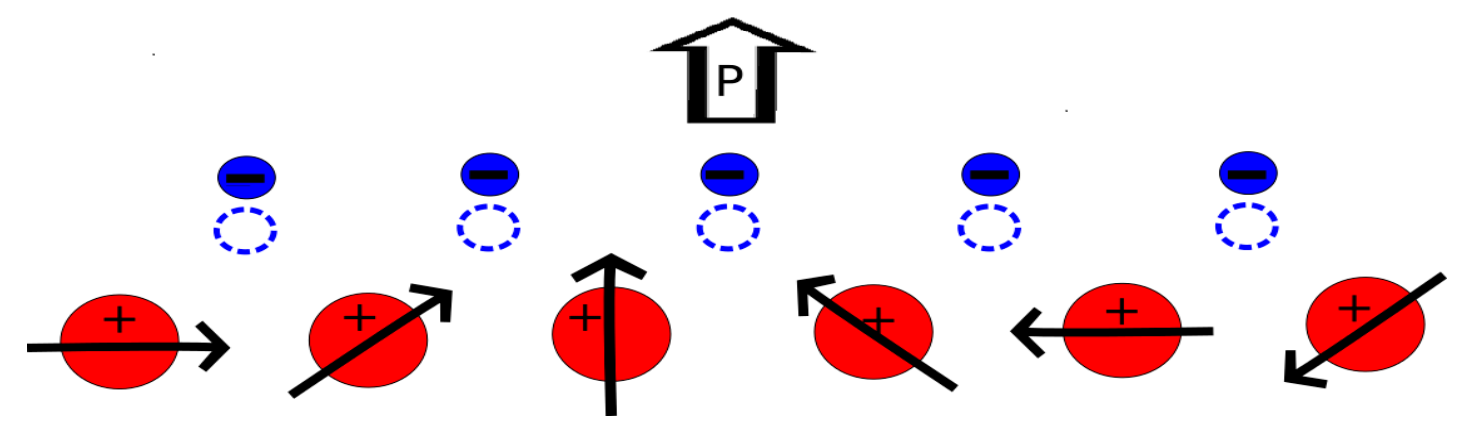

Figure 4. $\mathrm{Mn}^{3+}$ (red) spiral spin order will induce with the exchange striction a uniform displacement of the $\mathrm{O}^{2-}$ (blue) that breaks the space inversion symmetry and thus, induces a net electric polarization $(\mathrm{P})$.

\section{Magnetocaloric Properties of $\mathrm{RMnO}_{3}$ Multiferroic Crystals}

The $\mathrm{RMnO}_{3}(\mathrm{R}=$ rare earth) manganites have generated worldwide interest due to their rich physical properties and potential implementation in a wide range of applications going from spintronics such as four state memory systems [37] to magnetocaloric refrigeration [20-24,26,27]. In these highly frustrated multiferroics, the magnetic, electric and crystallographic structures are markedly coupled and strongly depend on the rare earth element size $\left(r_{R}\right)[22,27,65-68]$. Usually, the $\mathrm{RMnO}_{3}$ systems with larger ionic radius of $\mathrm{R}$ (typically $\mathrm{r}_{\mathrm{R}}>\mathrm{r}_{\mathrm{Dy}}$ ) crystallize in an orthorhombic structure illustrated in Figure 3 (Pbnm space group) [27,65-68]. This includes compounds such as $\mathrm{TbMnO}_{3}$ and $\mathrm{GdMnO}_{3}$ for example. When the ionic radius of $\mathrm{R}$ is smaller than that of $\mathrm{Dy}$ as in $\mathrm{HoMnO}_{3}$ and $\mathrm{ErMnO}_{3}$, the $\mathrm{RMnO}_{3}$ compounds form in a hexagonal structure with space group $\mathrm{P}_{3} \mathrm{~cm}$ [27,65-68]. It is worth noting that the $\mathrm{DyMnO}_{3}$ compound is usually more stable in the orthorhombic structure at room temperature. However, the free energies of both of its crystallographic structures (hexagonal and orthorhombic) are closer to each other [66]. Consequently, the hexagonal phase of $\mathrm{DyMnO}_{3}$ can also be stabilized under some special conditions, as reported in Ivanov et al. [66]. 
On the other hand, the origin of the ferroelectricity in orthorhombic and hexagonal $\mathrm{RMnO}_{3}$ is different. In orthorhombic multiferroics $\mathrm{RMnO}_{3}$, the ferroelectricity is directly generated by the complex magnetic structure that breaks the inversion symmetry $[49,65]$, which results in a strong coupling between magnetic and electric properties. For hexagonal phases, the spontaneous electric polarization arises from structural distortions that are induced by an asymmetric coordination of oxygen around the rare earth ions [65]. This usually gives rise to a weak magnetoelectric coupling and the ferroelectric order is retained up to $T_{C}=900 \mathrm{~K}$ that is far above the AFM ordering point of the $\mathrm{Mn}$-spins sublattice (around $80 \mathrm{~K}$ ) [26]. The orthorhombic and hexagonal symmetries of $\mathrm{DyMnO}_{3}$ could be considered as representatives of $\mathrm{RMnO}_{3}(\mathrm{R}=\mathrm{La}$ to Ho) multiferroics. In fact, although they contain the same rare earth (Dy) element, their magnetic and magnetocaloric properties differ markedly and have been widely documented in the literature [39-41,65-69].

The orthorhombic structure $\left(\mathrm{o}-\mathrm{DyMnO}_{3}\right)$ exhibits successive magnetic phase transitions that can be clearly seen from specific heat data [70]. First, the $\mathrm{Mn}^{3+}$ magnetic moments antiferromagnetically order in an incommensurate state close to $\mathrm{T}_{\mathrm{N} 1}=40 \mathrm{~K}$. Upon decreasing the temperature below $40 \mathrm{~K}$, the $\mathrm{Mn}^{3+}$ spins arrangement transforms into a longitudinal sinusoidal spin wave with a wave vector along the crystallographic axis b $[67,68]$. At around $T_{L}=18 \mathrm{~K}$, the ordered magnetic moments reveal a second component along the c-axis leading to a cycloidal (spiral) magnetic ordering. This breaks the inversion symmetry, leading to the appearance of a spontaneous electric polarization along the same crystallographic direction (c-axis). At temperatures below $15 \mathrm{~K}$, the $\mathrm{Dy}^{3+}$ magnetic moments manifest a sinusoidal incommensurate ordering along the b-axis [40]. Below $T_{\mathrm{N} 2}=6.5 \mathrm{~K}$ [40], the formed phase transforms into a commensurate antiferromagnetic state. By using neutron diffraction and X-ray resonant magnetic scattering techniques, Prokhnenko et al. [40] also pointed out the contribution of $\mathrm{Dy}^{3+}$ moments in enhancing the electric polarization in o- $\mathrm{DyMnO}_{3}$.

The magnetic properties of the hexagonal form $\left(\mathrm{h}-\mathrm{DyMnO} \mathrm{M}_{3}\right)$ are not well understood. $\mathrm{The}^{\mathrm{Mn}}{ }^{3+}$ moments order antiferromagnetically below $T_{\mathrm{N} 1}=60 \mathrm{~K}$ establishing triangular structures in the ab plane [65]. According to Nandi et al. [69], the $\mathrm{Dy}^{3+}$ magnetic moments are antiferromagnetically ordered along the c-axis at temperatures between $8 \mathrm{~K}$ and $68 \mathrm{~K}$. The ordering of $\mathrm{Dy}^{3+}$ spins in this temperature range is linked to the exchange field of $\mathrm{Mn}^{3+}$ through the $4 \mathrm{~d}-3 \mathrm{f}$ exchange interaction. However, by combining the optical second-harmonic generation and neutron diffraction, Wehrenfenning et al. [71] have revealed that $3 \mathrm{~d}-4 \mathrm{f}$ coupling in the $\mathrm{h}-\mathrm{DyMnO} \mathrm{O}_{3}$ compound is less rigid than suggested in previous studies. For temperatures below $T_{\mathrm{N} 2, \mathrm{Dy}}=10 \mathrm{~K}$, the rare earth magnetic moments in the $\mathrm{h}-\mathrm{DyMnO}_{3}$ crystal are ferrimagnetically aligned along the c-axis [65].

Isothermal magnetization curves of o- $\mathrm{DyMnO}$ and $\mathrm{h}-\mathrm{DyMnO}_{3}$ single crystals as a function of magnetic field applied along their easy and hard-directions at $2 \mathrm{~K}$ are presented in Figure 5 . As shown, the easy and hard-axes of the orthorhombic phase are clearly oriented along the $b$ and c directions, respectively. The magnetization along the hard-orientation evolves almost linearly even under high magnetic fields, while a saturation tendency can be clearly seen following the $\mathrm{b}$-axis for magnetic fields higher than $2 \mathrm{~T}$. The magnetization saturation value obtained at $2 \mathrm{~K}$ from Figure 5 is $170 \mathrm{Am}^{2} / \mathrm{kg}$ (about $8 \mu_{\mathrm{B}}$ ) being closer to the free $\mathrm{Dy}^{3+}$ moment value $\left(10 \mu_{\mathrm{B}}\right)$. This demonstrates the weak contribution of the Mn-sublattice to the full magnetization. On the other hand, the marked difference between magnetic isotherms along the crystallographic directions reveals a gigantic magneto-crystalline anisotropy in o- $\mathrm{DyMnO}_{3}$ crystals which is a common property of the orthorhombic $\mathrm{RMnO}_{3}$ manganites [39-41,65,67,72]. 


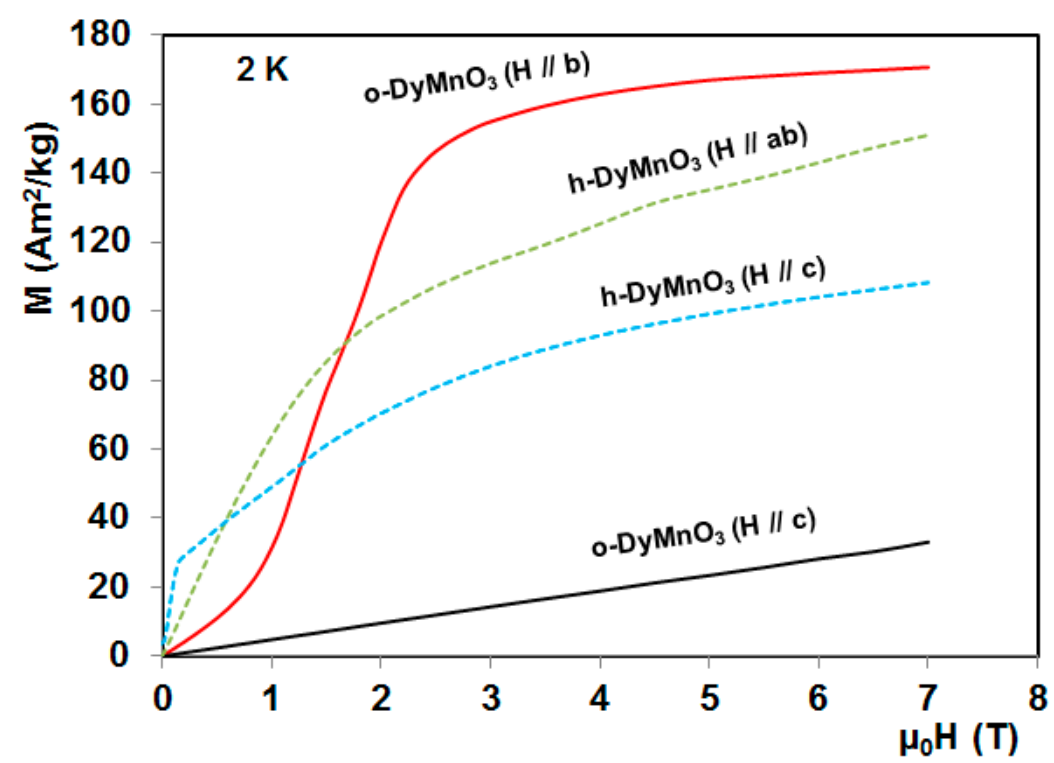

Figure 5. Isothermal magnetization curves at $2 \mathrm{~K}$ for orthorhombic (o) and hexagonal (h) $\mathrm{DyMnO}_{3}$ single crystals along their easy and hard-orientations [22,24].

In contrast to the orthorhombic phase, the h- $\mathrm{DyMnO}_{3}$ crystal unveils its easy axis along the c-orientation, while the hard-direction is parallel to the ab-plane. At $2 \mathrm{~K}$, the h- $\mathrm{DyMnO}_{3}$ magnetization under a magnetic field of $7 \mathrm{~T}$ applied along the c-axis is only $115 \mathrm{Am}^{2} / \mathrm{kg}$ being much lower than its equivalent of the orthorhombic phase $\left(170 \mathrm{Am}^{2} / \mathrm{kg}\right)[22,24]$. This can be mainly attributed to the ferrimagnetic ordering of $\mathrm{Dy}^{3+}$ moments that occupy non-equivalent crystallographic sites in the hexagonal form [65]. However, as shown in Figure 5 an enhancement of the h- $\mathrm{DyMnO}_{3}$ magnetization occurs when sufficiently high magnetic fields are applied within the ab-plane. Such behavior is not well understood, but the Mn lattice seems to contribute for this enhancement [22,65]. On the other hand, the o-DyMnO 3 magnetization exhibits a metamagnetic transition along the b-axis at low temperatures with a tendency to saturate under high magnetic fields (Figure 5). Such behavior is absent in isotherm curves reported by Harikrishnan et al. [65] following the same axis where the magnetization varies slightly with magnetic field. As showed by Balli et al. [24], the observed difference can be explained by the fact that the magnetic isotherms reported in Ref. [65] correspond more probably to the hard-axis c.

The magnetocaloric effect associated with the order-disorder type-magnetic transitions were recently explored in $\mathrm{DyMnO}_{3}$ phases (Figure 6a,b) and reported in $[22,24,26]$. The magnetocaloric properties of o- $\mathrm{DyMnO}_{3}$ single crystals have been explored around the ordering point of $\mathrm{Dy}^{3+}$ cations [24]. Along the easy-axis b, o- $\mathrm{DyMnO}_{3}$ unveils a giant magnetocaloric effect (Figure 6a) on a large working temperature range being a favorable situation from a practical point of view. Under magnetic variations of $0-7,0-5$ and $0-3$ T parallel to the easy axis $b$, the resulting isothermal entropy change $(-\Delta S)$ shows maximum values of about $17.25,14.6$ and $8.7 \mathrm{~J} / \mathrm{kg} \mathrm{K}$ [24], respectively, which are in good agreement with those reported by Midya et al. [26]. The adiabatic temperature change $\Delta T_{a d}$ was also estimated by Midya et al. according to isentropic curves using specific heat data [26]. It was found to be about $11.5 \mathrm{~K}$ under a magnetic field changing from 0 to $8 \mathrm{~T}$ along the b-axis [26]. For the hard-axis c, the induced entropy change is negligible and was found by Balli et al. [24] to be only $0.8 \mathrm{~J} / \mathrm{kg} \mathrm{K}$ in a magnetic field change of $0-7 \mathrm{~T}$ (Figure 6a). This value is 10 times lower than that reported in Ref. [26] following the hard-orientation (8 J/ $\mathrm{kg} \mathrm{K).} \mathrm{Looking} \mathrm{at} \mathrm{isothermal} \mathrm{magnetization}$ data reported in Ref. [26], it seems clearly that the large value of $-\Delta S$ along the hard-direction is rather related to the intermediate axis a [24]. On the other hand, the orthorhombic $\mathrm{DyMnO}_{3}$ shows a meaningful inverse (or negative) magnetocaloric effect at temperatures below $6 \mathrm{~K}$. This was mainly attributed to the antiferromagnetic ordering of $\mathrm{Dy}^{3+}$ magnetic moments in this temperature range. 
In fact, under the effect of an external magnetic field, the AFM phase transforms into a less ordered "ferromagnetic" one increasing then the material's magnetic entropy $[24,26]$.
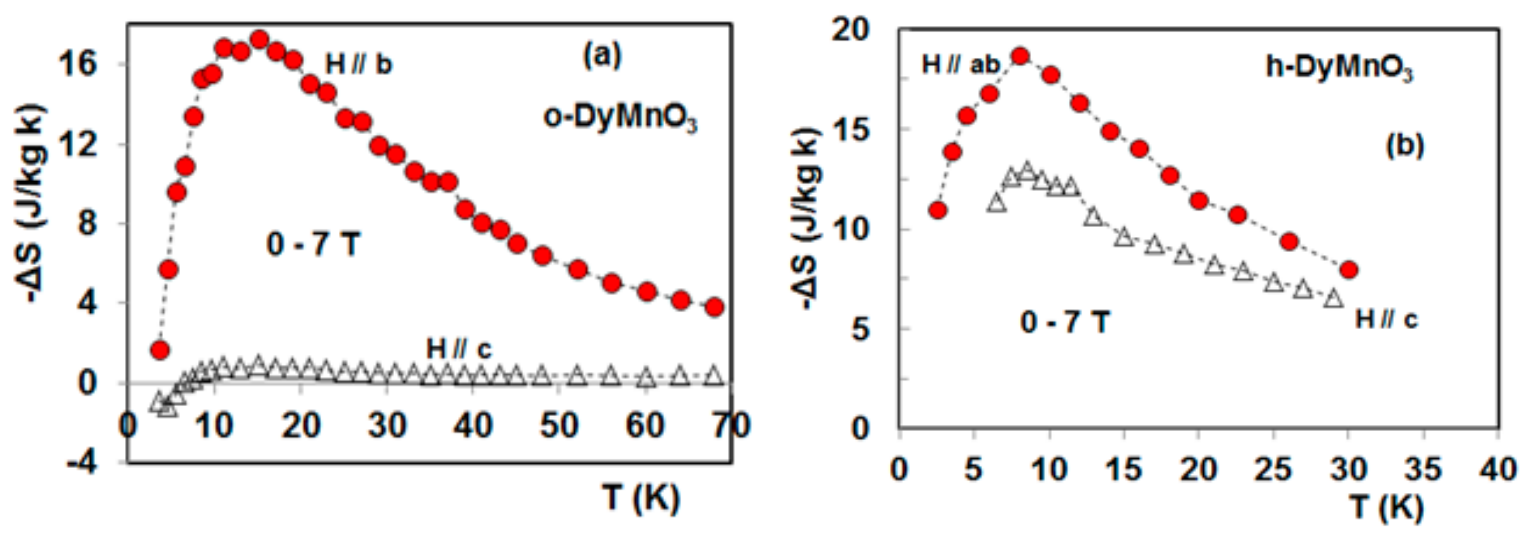

Figure 6. Isothermal entropy change as a function of temperature under a magnetic field change of $7 \mathrm{~T}$ along the easy and hard-directions of orthorhombic (a) and hexagonal (b) $\mathrm{DyMnO}_{3}$ single crystals $[22,24]$.

The rotating magnetocaloric effect was also investigated in the orthorhombic $\mathrm{DyMnO}_{3}$ single crystal [24]. In fact, the latter reveals a gigantic anisotropy of the magnetocaloric effect. As shown in Figure 6a, the maximum entropy change under $7 \mathrm{~T}$ applied parallel to the easy axis is more than 20 times larger than that along the hard-axis c. This means that thermal effects can also be induced by rotating o- $\mathrm{DyMnO}_{3}$ crystals between their hard and easy-axes in constant magnetic fields (Figure 7a,b). As reported in [24], the resulting entropy change from a $90^{\circ}$ rotation in the bc-plane reaches maximum values of $8.4,14.2$, and $16.3 \mathrm{~J} / \mathrm{kg} \mathrm{K}$ in constant magnetic fields of 3, 5, and $7 \mathrm{~T}$, respectively. The associated adiabatic temperature change was found to be 5, 9, and $11 \mathrm{~K}$, respectively. It should be noticed that the reported rotating adiabatic temperature change in [24] is similar to the $\Delta T_{a d}$ obtained by Midya et al. [26] from the magnetization of o- $\mathrm{DyMnO}_{3}$ along the easy-axis b $(10.5 \mathrm{~K}$ in $0-7 \mathrm{~T}$ ). This can be explained by the fact that the full entropy along the hard-axis is practically equal to that shown in the absence of magnetic field since $\Delta S(H / / c)$ is negligible [24].
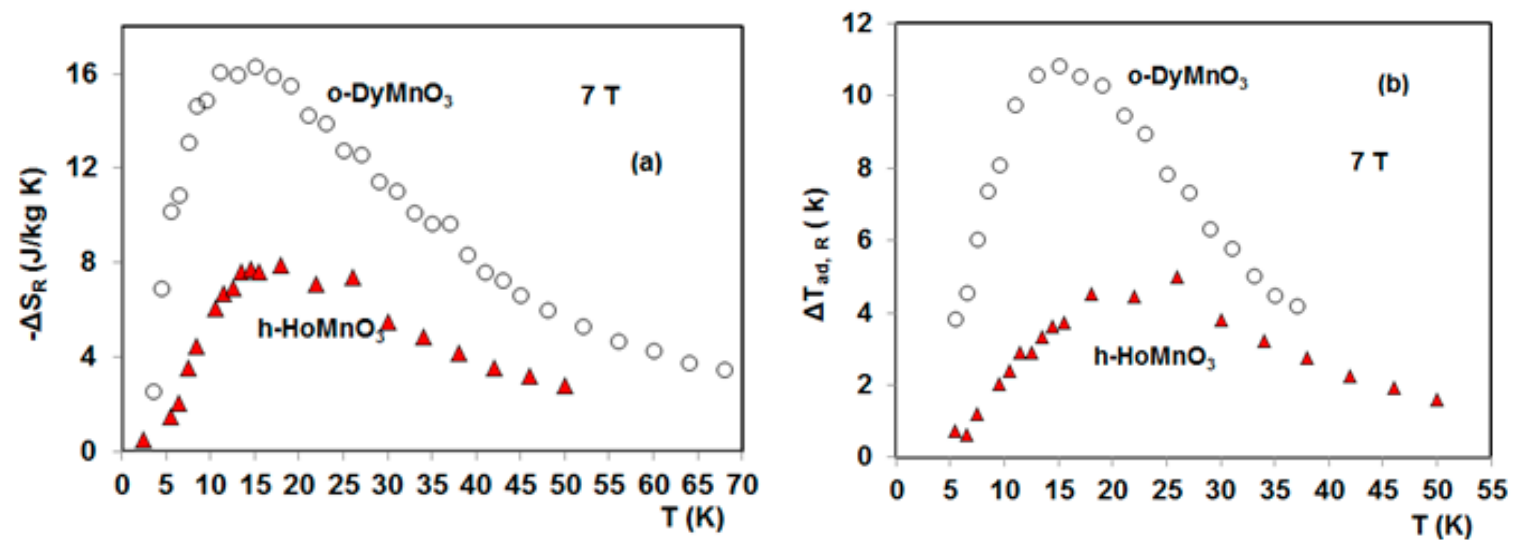

Figure 7. (a) Rotating entropy change as a function of temperature under a constant magnetic field of $7 \mathrm{~T}$ for orthorhombic $\mathrm{DyMnO}_{3}$ and hexagonal $\mathrm{HoMnO}_{3}$. (b) Associated adiabatic temperature change [24,27].

In comparison with o- $\mathrm{DyMnO}$, the magnetic anisotropy is less pronounced in the hexagonal phase (Figure 5). The h-DyMnO 3 magnetocaloric properties were more recently investigated by 
Balli et al. [22]. Along the ab plane, it was found that the position of $\Delta S_{\max }$ varies from 3 to $8 \mathrm{~K}$ when the magnetic field strength is changed from $0-2 \mathrm{~T}$ to $0-7 \mathrm{~T}$. For the easy-axis $\mathrm{c}$, the h-DyMnO isothermal entropy change curves remain peaked (Figure $6 \mathrm{~b}$ ) on the $\mathrm{Dy}^{3+}$ transition temperature (8 K) even under high magnetic fields [22]. On the other hand, for sufficiently high magnetic fields, Balli et al. [22] showed that the entropy change associated within the ab-plane is much larger than that along the c-axis (Figure $6 \mathrm{~b}$ ). For field changes of $0-2,0-5$, and $0-7 \mathrm{~T}$, the maximum entropy change $\left(-\Delta S_{\max }\right)$ shown by the hexagonal $\mathrm{DyMnO}_{3}$ was found to be 8,15 , and $19 \mathrm{~J} / \mathrm{kg} \mathrm{K}$ for $\mathrm{H} / / \mathrm{ab}$ while it is 5,10 , and $13 \mathrm{~J} / \mathrm{kg} \mathrm{K}$ for $\mathrm{H} / / \mathrm{c}$. The corresponding adiabatic temperature changes were found to be $2.86,12.24$, and $15 \mathrm{~K}$ for $\mathrm{H} / / \mathrm{ab}$ while those for $\mathrm{H} / / \mathrm{c}$ are 4.33 , 8.6, and $11.2 \mathrm{~K}$, respectively. As reported, the resulting $-\Delta S$ in h-DyMnO 3 under a magnetic field changing from 0 to $5 \mathrm{~T}$ in the ab plane, exceeds that shown along the c-axis by nearly $50 \%$ [22]. This was mainly attributed to the enhancement of the magnetization under high magnetic fields applied within the ab-plane [22]. Additionally, a large MCE that can be obtained under very low magnetic fields was pointed out in h-DyMnO 3 crystals by Balli et al. [22] along the c-axis. When varying the magnetic field along the easy axis $\mathrm{c}$ from 0 to $0.2,0$ to 0.3 , and 0 to $0.5 \mathrm{~T},-\Delta S_{\max }$ reaches values of $1,1.5$, and $2 \mathrm{~J} / \mathrm{kg} \mathrm{K}$. This is of great importance from a practical point view since such low magnetic fields can be easily produced by using "cheaper" permanent magnets [16,73]. In contrast, $-\Delta S$ is negligible under low magnetic fields applied within the ab plane. This was attributed to the instability of the antiferromagnetic phase (along c-axis) near the ordering temperature of $\mathrm{Dy}^{3+}$ magnetic moments in h-DyMnO $3[22,66]$. In the vicinity of $8 \mathrm{~K}$, a metamagnetic transition from an antiferromagnetic to a ferrimagnetic state can be induced under very low magnetic fields applied along the c-axis, leading to interesting levels for MCE.

The magnetocaloric properties of $\mathrm{HoMnO}_{3}$ single crystals were investigated by Balli et al. [27] and Midya et al. [26]. Even though this compound shows some structural similarities with the hexagonal $\mathrm{DyMnO}_{3}$, their magnetic features are quite different [27]. For the $\mathrm{HoMnO}_{3}$ single crystal which forms in a hexagonal structure with space group $\mathrm{P} 63 \mathrm{~cm}$, the "easy direction" is rather along the ab-plane while the hard-axis is oriented along the c-axis (Figure 8), which markedly contrast with the hexagonal $\mathrm{DyMnO}_{3}$ [22]. In h-HoMnO 3 , the $\mathrm{Mn}^{3+}$ magnetic moments usually order in an antiferromagnetic structure below $T_{\mathrm{N} 1}=75 \mathrm{~K}$ and rotate in ab-plane by an angle of $90^{\circ}$ at around $T_{s r}=40 \mathrm{~K}$. This spin reorientation initiates a partial ordering of $\mathrm{Ho}^{3+}$ magnetic moments because of the coupling between $\mathrm{Mn}^{3+}$ and $\mathrm{Ho}^{3+}$ spins $[26,27,74-79]$. A more ordered state of $\mathrm{Ho}^{3+}$ magnetic moments takes place bellow $T_{\mathrm{N} 2}=5 \mathrm{~K}[26,27,74-79]$.

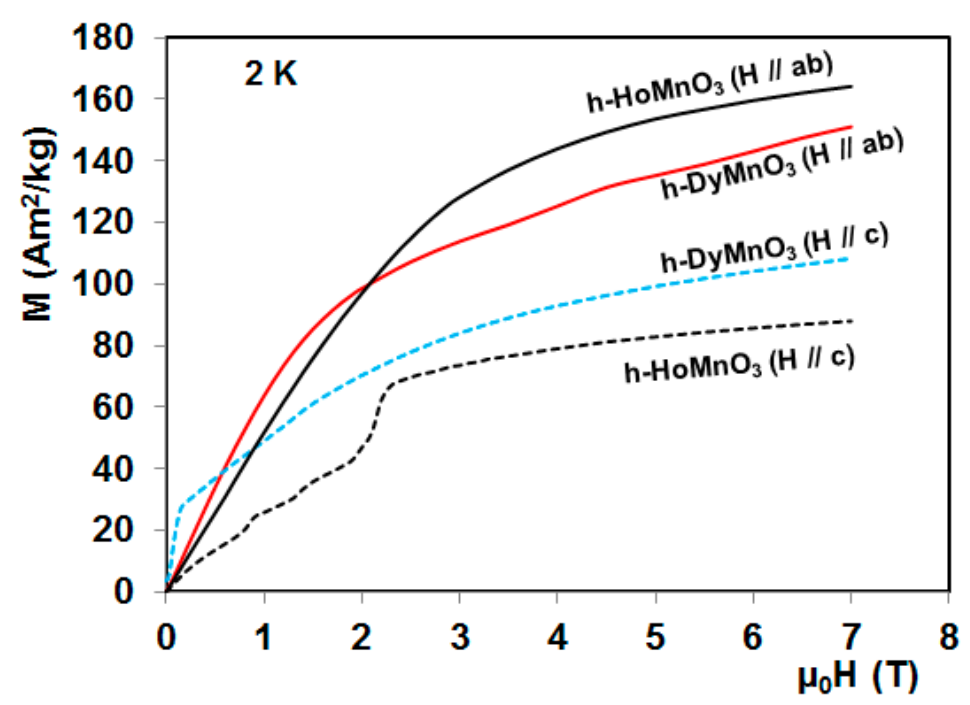

Figure 8. Isothermal magnetization curves at $2 \mathrm{~K}$ for hexagonal $\mathrm{DyMnO}_{3}$ and $\mathrm{HoMnO}_{3}$ single crystals along their easy- and hard-directions $[22,27]$. 
It is worth noting that the magnetic structure of $\mathrm{Ho}^{3+}$ ions in the h-HoMnO 3 compound is not yet well elucidated even though a large number of studies addressing this issue have been reported in the literature [74-79]. However, based on early works, Hur et al. [79] have established a more plausible magnetic structure in which the $\mathrm{Ho}^{3+}$ magnetic moments are strongly in plane coupled (antiferromagnetically) via the $\mathrm{Ho}(4 \mathrm{~b})-\mathrm{Ho}(4 \mathrm{~b})$ exchange interaction leading to non-uncompensated in-plane moments. On the 2a site, the $\mathrm{Ho}^{3+}$ spins show a disordered feature [79]. Additionally, below $T_{s r}$ the $\mathrm{Ho}^{3+}$ magnetic moments are ordered along the c-axis with a ferrimagnetic arrangement in the ab-plane [79]. On the other hand, the strong antiferromagnetic interplay between the $\mathrm{Mn}^{3+}$ magnetic moments through triangular sublattices in the ab-plane makes the Mn-lattice contribution to the full magnetization negligible [74].

As shown in Figure 8, the h-HoMnO 3 magnetization shows an anisotropic behavior between the c-axis and the ab-plane. At $2 \mathrm{~K}$, it was found that the magnetization under $7 \mathrm{~T}$ reaches about $7.872 \mu_{\mathrm{B}} / \mathrm{f}$.u for $\mathrm{H} / / \mathrm{ab}$ and only $4.22 \mu_{\mathrm{B}} / \mathrm{f}$.u for $\mathrm{H} / / \mathrm{c}$, being about $80 \%$ and $42 \%$ of the $\mathrm{Ho}^{3+}$ individual magnetic moments $\left(10 \mu_{\mathrm{B}}\right)[27,80]$, respectively. On the other hand, a first metamagnetic transition clearly occurs in h-HoMnO 3 under magnetic fields higher than $2 \mathrm{~T}$ applied along the c-axis [27]. The corresponding critical magnetic field evolves linearly as a function of temperature with a rate of $0.1714 \mathrm{~T} / \mathrm{K}$.

A second field-induced phase transition was observed in some h-HoMnO 3 crystals under a magnetic field of $6.5 \mathrm{~T}$ applied along the same axis [81]. This could originate from the ordering of 2a site moments that show a disordered feature. However such metamagnetic transformation is not visible in magnetization data reported in [27] up to $7 \mathrm{~T}$ (see also Figure 8).

The magnetocaloric properties of $\mathrm{h}-\mathrm{HoMnO}_{3}$ single crystals have been carried out by Balli et al. [27] and Midya et al. [26,75]. The reported data demonstrate that the MCE shown by h- $\mathrm{HoMnO}_{3}$ is similar to that exhibited by the $\mathrm{DyMnO}_{3}$ hexagonal phase. As a consequence of the magnetic anisotropy, the obtained isothermal entropy change along the ab-plane largely exceeds that along the c-axis, particularly under sufficiently high applied magnetic fields (Figure 9a,b). Under field variations of $0-2,0-5$, and $0-7 \mathrm{~T}$ parallel to the ab-plane, the h-HoMnO 3 compound produces a maximum entropy change of $3.86,13.9$, and $18.7 \mathrm{~J} / \mathrm{kg} \mathrm{K}$, respectively. Along the c-axis, $-\Delta S_{\max }$ was evaluated to be $2.86,11.24$, and $13.2 \mathrm{~J} / \mathrm{kg} \mathrm{K}$, respectively [27]. These values are quite similar to those reported by Midya et al. [26]. The adiabatic temperature change was found to be 10.8 and $6 \mathrm{~K}$ under a magnetic field change of $7 \mathrm{~T}$ applied along the ab-plane and the c-axis, respectively [27]. According to Balli et al. [27], the $\mathrm{MCE}$ corresponding to the c-axis in h- $\mathrm{HoMnO}_{3}$ arises mainly from the field-induced metamagnetic transition zone, particularly under magnetic fields lower than $3.5 \mathrm{~T}$. However, the entropy change associated with the metamagnetic region in $\mathrm{h}-\mathrm{HoMnO}_{3}$ was found to be several times larger than its equivalent in the hexagonal $\mathrm{DyMnO}_{3}[22,27]$, as a consequence of their distinguished magnetic structures.

Taking advantage of the magnetic anisotropy, the rotating magnetocaloric effect has been investigated in the h-HoMnO 3 single crystal and reported in Balli et al. [27]. The rotation of h- $\mathrm{HoMnO}_{3}$ around the a (or b) axis in a constant magnetic field of $7 \mathrm{~T}$ enables a maximum entropy change of $8 \mathrm{~J} / \mathrm{kg}$ $\mathrm{K}$ to be generated and a maximum temperature change of about $5 \mathrm{~K}$. As shown in Figure 7 , the produced RMCE in terms of both $\Delta T_{a d}$ and $\Delta S$ is lower than that shown by the orthorhombic $\mathrm{DyMnO}_{3}$. This can mainly be explained by the gigantic magnetocrystalline anisotropy usually exhibited by orthorhombic $\mathrm{RMnO}_{3}$ manganites [24] as shown in Figure 6. 

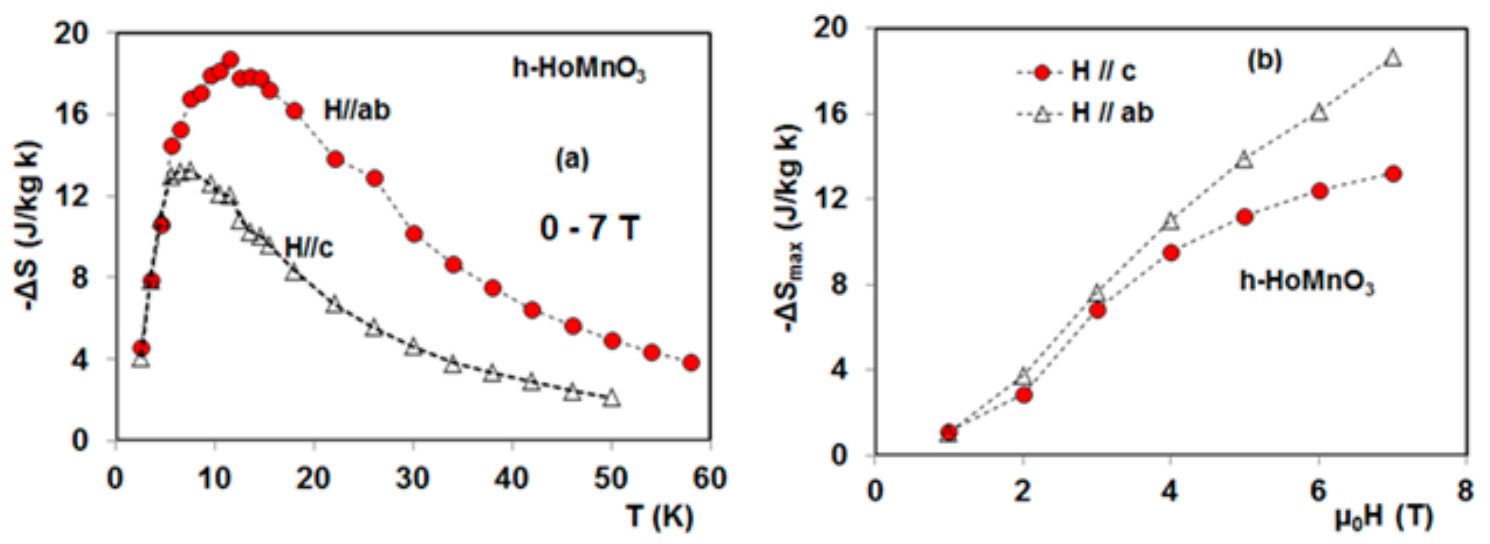

Figure 9. (a) Isothermal entropy change as a function temperature of the hexagonal $\mathrm{HoMnO}_{3}$ for a magnetic field variation from 0 to $7 \mathrm{~T}$ along the easy and hard-directions. (b) Its maximum value as a function of magnetic field [27].

The magnetocaloric characteristics of the orthorhombic perovskite $\mathrm{TbMnO}_{3}$ single crystal were reported in Jin et al. [21] and Midya et al. [26]. According to early works [21,26,59,82,83], its $\mathrm{Mn}^{3+}$ magnetic moments order in an incommensurate phase below the Néel temperature $T_{\mathrm{N} 1}=42 \mathrm{~K}$. A second magnetic phase transition to a commensurate state of $\mathrm{Mn}^{3+}$ moments takes place at $T_{L}=27 \mathrm{~K}$. Below $T_{L}$ the $\mathrm{Mn}^{3+}$ magnetic moments rotate in the bc-plane to form a spiral magnetic structure with the propagation vector along the b-axis. This results in a spontaneous electric polarization along the c-axis. The $\mathrm{Tb}^{3+}$ magnetic moments usually order below $T_{\mathrm{N} 2}=7 \mathrm{~K}[21,26,59,82,83]$. However, in the work by Jin et al. [21], the ordering temperature of $\mathrm{Tb}^{3+}$ moments was evaluated to be about $9 \mathrm{~K}$. In Ref. [21], the magnetization and MCE data were only reported along the $\mathrm{a}$ and $\mathrm{b}$ axes under magnetic fields up to $7 \mathrm{~T}$. Along the a-axis, magnetization isotherms unveil a "metamagnetic" transition at low temperatures to reach a nearly saturation state $\left(7.1 \mu_{\mathrm{B}} / \mathrm{f} . \mathrm{u}\right)$ after overpassing a critical magnetic field of about 1.4 T. This behavior originates from the switch of the spiral magnetic structure from the bc-plane to the ac-plane under the effect of an external magnetic field as a consequence of the strong coupling between $\mathrm{Tb}^{3+}$ and $\mathrm{Mn}^{3+}$ magnetic moments [21]. As for the a-axis, the change in the spiral magnetic structure leads to a sharp transition under a magnetic field of $4.8 \mathrm{~T}$ applied along the b-axis, while a change in the wave vector modulation induces a second magnetic transition under a low magnetic field of $0.8 \mathrm{~T}$ [21]. All these magnetic features lead to interesting levels for the magnetocaloric effect in $\mathrm{TbMnO}_{3}$ single crystals [21].

In the field change of $7 \mathrm{~T}$ applied along the easy-axis a, $\mathrm{TbMnO}_{3}$ exhibits a reversible maximum entropy change $-\Delta S_{\max }=18 \mathrm{~J} / \mathrm{kg} \mathrm{K}$ which compares well with that reported in $\mathrm{HoMnO}_{3}$ [27] and $\mathrm{DyMnO}_{3}[22,24]$ along their easy directions. The corresponding adiabatic temperature change was found by Midya et al. [26] to be about $10.5 \mathrm{~K}$. For H//b, the maximum entropy change shown by $\mathrm{TbMnO}_{3}$ is only about $10 \mathrm{~J} / \mathrm{kg} \mathrm{K}$ (under $7 \mathrm{~T}$ ) due to the magnetocrystalline anisotropy. It is also worth noting that below the ordering point of $\mathrm{Tb}^{3+}$ spins $(9 \mathrm{~K})$, the $\mathrm{TbMnO}_{3}$ single crystal shows a negative MCE under relatively low magnetic fields applied along its a-axis. This mainly originates from the suppression of the "more ordered" antiferromagnetic state, giving rise to a positive entropy change [21]. The MCE becomes conventional under sufficiently high magnetic fields since the magnetic phase is transferred to a more ordered ferromagnetic state [21]. However, along the b-axis the negative feature of the MCE is retained up to $7 \mathrm{~T}$. This mainly arises from the strong antiferromagnetic interplay between the $\mathrm{Mn}^{3+}$ and $\mathrm{Tb}^{3+}$ moments in the bc-plane [21]. Additionally, the $\mathrm{TbMnO}_{3}$ single crystal unveils a maximum anisotropic entropy change of about $8 \mathrm{~J} / \mathrm{Kg} \mathrm{K}$ [21] in a magnetic field of $7 \mathrm{~T}$, being much lower than that found in the orthorhombic $\mathrm{DyMnO}_{3}$ (16.3 J/kg K under $\left.7 \mathrm{~T}\right)$ [24]. On the other hand, the rotation of the $\mathrm{TbMnO}_{3}$ single crystal in a constant magnetic field of $5 \mathrm{~T}$ between a and $\mathrm{b}$ axes enables a maximum adiabatic temperature change of about $6 \mathrm{~K}$ to be achieved [21]. 
In a following paper, Jin et al. [23] explored the magnetocaloric properties of $\mathrm{TmMnO}_{3}$ single crystals. This compound belongs to the family of hexagonal $\mathrm{RMnO}_{3}$ manganites such as $\mathrm{h}-\mathrm{HoMnO}$ and $\mathrm{h}-\mathrm{DyMnO} \mathrm{M}_{3}$ compounds discussed above. In this crystal, the Néel temperature associated with the ordering of $\mathrm{Mn}^{3+}$ magnetic moments was observed around $83 \mathrm{~K}$ [84]. Below this temperature, the $\mathrm{Tm}^{3+}$ ions unveil a magnetic moment at the $4 \mathrm{~b}$ crystallographic site due to the Tm-Mn exchange interaction, while the 2a site shows a paramagnetic character down to $4.2 \mathrm{~K}$ [84]. This was particularly confirmed by Mossbauer data reported in Salama et al. [84]. The ordering temperature of $\mathrm{Tm}^{3+}$ was reported in the literature to be lower than $1.8 \mathrm{~K}$ [85]. As reported in [23], the hexagonal $\mathrm{TmMnO}_{3}$ shows large magnetic and magnetocaloric anisotropies between the $\mathrm{c}$ and a axes. For $\mathrm{H} / / \mathrm{c}$, its magnetization reaches a value of $4.9 \mu_{\mathrm{B}} /$ f.u (under $7 \mathrm{~T}$ ) at $2 \mathrm{~K}$ and only about $0.8 \mu_{\mathrm{B}} / \mathrm{f}$.u for $H / / a$ (under $7 \mathrm{~T}$ ) [23]. The resulting maximum entropy change from the magnetization of $\mathrm{TmMnO}_{3}$ along the c-axis was reported to be $8.73 \mathrm{~J} / \mathrm{kg} \mathrm{K}$ in the field of $7 \mathrm{~T}$, which is more than two times lower if compared with other $\mathrm{RMnO}_{3}$ compounds $(\mathrm{R}=\mathrm{Ho}, \mathrm{Dy}, \mathrm{Tb})[21,22,24,27]$. This can be partly attributed to the partial ordering of the $\mathrm{Tm}^{3+}$ ions magnetic moment [84]. Along the a-axis, the entropy change in $\mathrm{TmMnO}_{3}$ was found to be negligible [23].

The magnetocaloric properties of the hexagonal $\mathrm{YbMnO}_{3}$ were briefly discussed in [26]. According to early neutron diffraction and Mossbauer spectroscopy data [86], the hexagonal form of $\mathrm{YbMnO}_{3}$ shows the antiferromagnetic ordering of $\mathrm{Mn}^{3+}$ magnetic moments at around $T_{\mathrm{N} 1}=85 \mathrm{~K}$. This is accompanied by a partial ordering of $\mathrm{Yb}^{3+}$ magnetic moments at the $4 \mathrm{~b}$ site through $\mathrm{Yb}-\mathrm{Mn}$ exchange interactions. At temperatures below $3.5 \mathrm{~K}$, the rest of the $\mathrm{Yb}^{3+}$ magnetic moments orders at the $2 \mathrm{a}$ site via $\mathrm{Yb}-\mathrm{Yb}$ magnetic exchanges [86]. Midya et al. [26] found that the magnetic behavior of $\mathrm{h}-\mathrm{YbMnO} 3$ is less anisotropic with strong antiferromagnetic interactions along the $\mathrm{c}$ and a axes. On the other hand, the $\mathrm{h}-\mathrm{YbMnO}_{3}$ compound was found to present distinguished features depending on the a and c crystallographic axes. While the magnetization increases slightly with magnetic field applied along the a-axis, an abrupt change can be observed under magnetic fields higher than $3 \mathrm{~T}$ applied along the c-axis at low temperatures [26]. The maximum isothermal entropy change was evaluated to be about $7.24 \mathrm{~J} / \mathrm{kg} \mathrm{K}$ under a magnetic field change of $7 \mathrm{~T}$, being much lower than that shown by the hexagonal $\mathrm{HoMnO}_{3}$, for example [27]. This can be mainly attributed to the smaller value of the $\mathrm{Yb}^{3+}$ magnetic moment which is about $4 \mu_{\mathrm{B}}$ [80]. However, despite the moderate value of $\Delta S$, its adiabatic temperature change shows a maximum value that largely exceeds that exhibited by the $\mathrm{RMnO}_{3}$ compounds discussed above. Until now, the physics behind this enhancement has remained unclear.

The magnetocaloric properties of other $\mathrm{RMnO}_{3}$ compounds such as $\mathrm{GdMnO}_{3}[87,88], \mathrm{NdMnO}_{3}$ [89], $\mathrm{SmMnO}_{3}$ [90], and $\mathrm{EuMnO}_{3}$ [91] were also investigated. In contrast with other o- $\mathrm{RMnO}_{3}$ manganites, the orthorhombic $\mathrm{GdMnO}_{3}$ ground state unveils a canted A-type antiferromagnetism [88]. According to magnetization measurements and specific heat data, three phase transitions can be clearly identified [87]. At around $T_{\mathrm{N} 1}=42 \mathrm{~K}$, the $\mathrm{Mn}^{3+}$ magnetic moments order in an incommensurate antiferromagnetic state. This latter transforms into a canted A-type antiferromagnetic phase at $23 \mathrm{~K}$. On decreasing temperature, the ordering of $\mathrm{Gd}^{3+}$ spins takes place at $5.2 \mathrm{~K}$. Kimura et al. [67] reported that the $\mathrm{GdMnO}_{3}$ compound manifests a multiferroic feature when subjected to external magnetic fields. The application of magnetic fields along the $b$-axis generates an electric polarization along the a-axis [67]. This is in contradiction to Hemberger et al. [88] who claimed the absence of ferroelectricity in $\mathrm{GdMnO}_{3}$ as a result of non-spiral character of the magnetic ground state.

The magnetocaloric properties of the $\mathrm{GdMnO}_{3}$ single crystal were more recently reported by Wagh et al. [87] along its crystallographic axes. Under a magnetic field changing from 0 to $8 \mathrm{~T}$ along the c-axis around the ordering point of $\mathrm{Dy}^{3+}$ magnetic moments $(7 \mathrm{~K})$, a large isothermal entropy change of about $31.8 \mathrm{~J} / \mathrm{kg} \mathrm{K}$ can be reached. Along the a and b-axes the calculated $-\Delta S$ is slightly lower and found to be about 29.1 and $25.7 \mathrm{~J} / \mathrm{kg} \mathrm{K}$, in a similar magnetic field, respectively. On the other hand, the $\mathrm{GdMnO}_{3}$ single crystal unveils a negative magnetocaloric effect following the a and c-axes. This was attributed by the authors [87] to the antiferromagnetic ordering of $\mathrm{Gd}^{3+}$ magnetic moments. 
For $\mathrm{NdMnO}_{3}$, relatively low values of $\mathrm{MCE}$ were reported by Chandra et al. [89]. Under a magnetic field change of $5 \mathrm{~T}$, the bulk polycrystalline $\mathrm{NdMnO}_{3}$ shows a maximum of about $4.4 \mathrm{~J} / \mathrm{kg} \mathrm{K}$ for $-\Delta S$ at $15 \mathrm{~K}$. The entropy change of its nanocrystalline $(40 \mathrm{~nm})$ form exhibits two different maxima of about 2.3 and $3.7 \mathrm{~J} / \mathrm{kg} \mathrm{K}$ (under $5 \mathrm{~T}$ ) at 70 and $15 \mathrm{~K}$, respectively. For the polycrystalline $\mathrm{SmMnO}_{3}$, a maximum entropy change of about $9 \mathrm{~J} / \mathrm{kg} \mathrm{K}$ was reported for a magnetic field change of $7 \mathrm{~T}$ around $\mathrm{T}_{\mathrm{N}}=57 \mathrm{~K}$ [90]. A similar value was also found at $9 \mathrm{~K}$ under the same magnetic field [90]. Regarding the $\mathrm{EuMnO}_{3}$ compound, a negligible MCE in terms of $\Delta S$ and $\Delta T_{a d}$ was reported by Sagar et al. [91].

The refrigerant capacity and the isothermal entropy change along the easy-axis of some relevant $\mathrm{RMnO}_{3}$ single crystals are reported in Figures 10 and 11. As shown, the RC is particularly higher for compounds containing rare earth element with high magnetic moments such as $\mathrm{Tb}, \mathrm{Ho}$, and $\mathrm{Dy}$. The largest RC is presented by the orthorhombic $\mathrm{DyMnO}_{3}$ (452 J/kg under $7 \mathrm{~T}$ ) [24]. The exhibited $\mathrm{RC}$ largely exceeds that shown by some of the best intermetallics such as $\mathrm{ErRu}_{2} \mathrm{Si}_{2}(196.5 \mathrm{~J} / \mathrm{kg}$ for $5 \mathrm{~T})$ [92], but remain much lower when compared with the vanadate $\mathrm{HoVO}_{3}(620 \mathrm{~J} / \mathrm{kg}$ under $7 \mathrm{~T})$ [28]. For $-\Delta S$, the largest value is shown by the $\mathrm{GdMnO}_{3}$ single crystal. This is probably attributed to a more pronounced first order phase transition associated with the ordering of $\mathrm{Gd}^{3+}$ spins. However, its adiabatic temperature change [87] remains comparable with that shown by other orthorhombic $\mathrm{RMnO}_{3}(\mathrm{R}=\mathrm{Tb}$, Dy) [21,24].

In addition to $\mathrm{RMnO}_{3}$ manganites, the $\mathrm{RTiO}_{3}$ (titanates) [93-95] and $\mathrm{RFeO}_{3}$ [96] compounds emerge also as promising magnetocaloric materials for cryogenic applications. Particularly, a giant magnetocaloric effect was pointed out in $\mathrm{EuTiO}_{3}$ single crystals [93]. Around the antiferromagnetic ordering point of $\mathrm{Eu}^{2+}$ magnetic moments $\left(\mathrm{T}_{\mathrm{N}}=5.8 \mathrm{~K}\right)$, a huge isothermal entropy change of $49 \mathrm{~J} / \mathrm{kg}$ under $7 \mathrm{~T}$ was more recently reported by Midya et al. [93]. In a similar magnetic field, the associated adiabatic temperature change and the refrigerant capacity were found to be $21 \mathrm{~K}$ and $500 \mathrm{~J} / \mathrm{kg} \mathrm{K}$, respectively. The reported $\Delta S$ and $\Delta T_{a d}$ in $\mathrm{EuTiO}_{3}$ [93] largely exceed those shown by the here reviewed $\mathrm{RMnO}_{3}$ manganites. However, its refrigerant capacity remains comparable with that presented by the orthorhombic $\mathrm{DyMnO}_{3}$ (Figure 11) but lower if compared with the $\mathrm{HoVO}_{3}$ vanadate [28]. On the other hand a large rotating entropy change that is comparable with that exhibited by o- $\mathrm{DyMnO}_{3}$ crystals [24] was more recently reported in $\mathrm{TbFeO}_{3}\left(-\Delta \mathrm{S}_{\mathrm{R}}=17.42 \mathrm{~J} / \mathrm{kg} \mathrm{K}\right.$ at $\left.5 \mathrm{~T}\right)$ around $9 \mathrm{~K}$ [96]. These data underline the high potential of $\mathrm{R}(\mathrm{Ti}, \mathrm{Fe}) \mathrm{O}_{3}$-based compounds in cryomagnetocaloric applications.

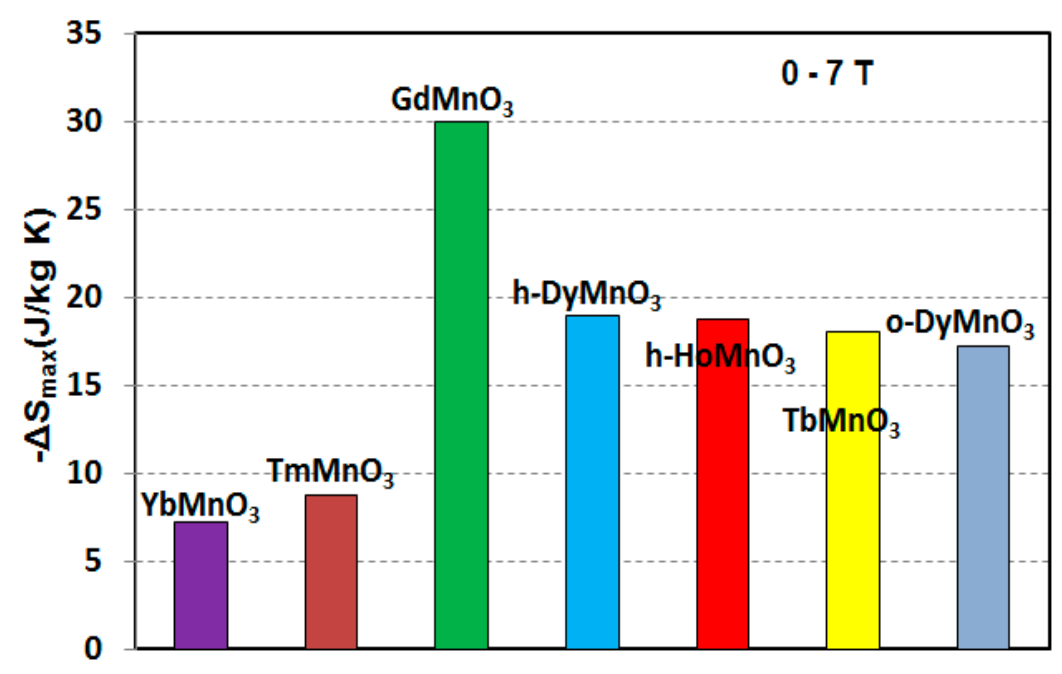

Figure 10. Maximum entropy change of $\mathrm{RMnO}_{3}$ single crystals under a magnetic field of $7 \mathrm{~T}$ applied along their easy directions, with $\mathrm{R}=\mathrm{Yb}$ [26], Tm [23], Gd [87], h-Dy [22], h-Ho [27], Tb [21], and o-Dy [24]. 


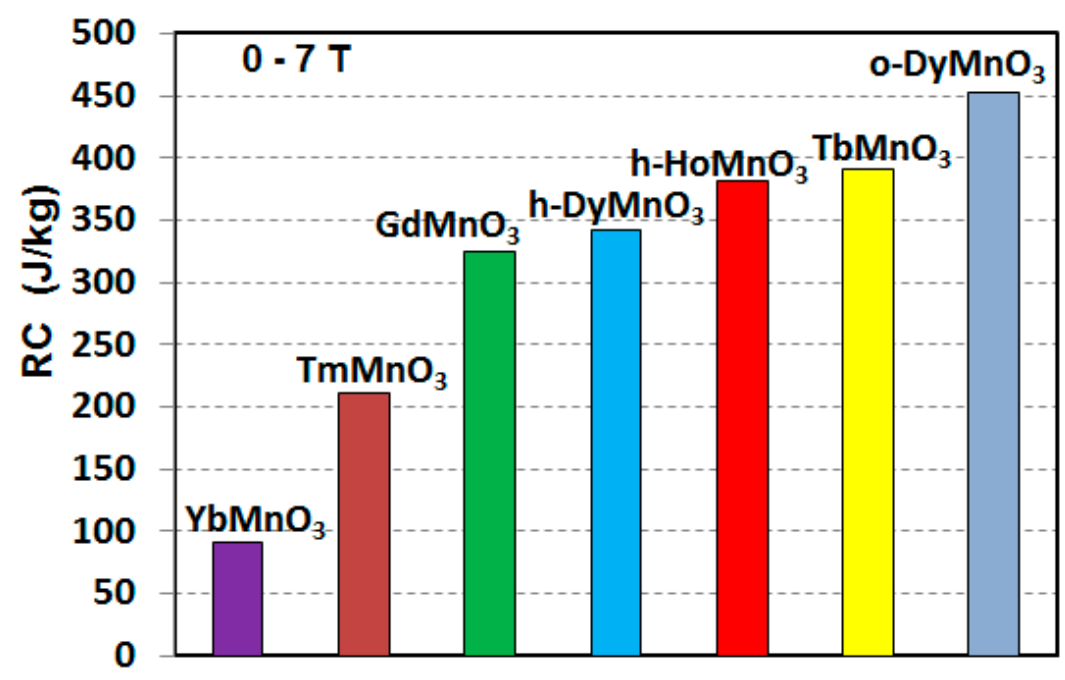

Figure 11. Refrigerant capacity of $\mathrm{RMnO}_{3}$ single crystals under a magnetic field of $7 \mathrm{~T}$ applied along their easy directions, with $\mathrm{R}=\mathrm{Yb}$ [26], Tm [23], Gd [87], h-Dy [22], h-Ho [27], Tb [21], and o-Dy [24].

\section{Magnetocaloric Properties of $\mathrm{RMn}_{2} \mathrm{O}_{5}$ Multiferroic Crystals}

Several studies of $\mathrm{RMn}_{2} \mathrm{O}_{5}$ ( $\mathrm{R}=$ rare earth) oxides have revealed a giant magnetoelectric effect (MEE), which is associated with an unusual commensurate-incommensurate magnetic phase transition. In the case of $\mathrm{DyMn}_{2} \mathrm{O}_{5}$, the dielectric constant was enhanced by more than $100 \%$ under the application of an external magnetic field leading to a colossal magnetodielectric effect (CMD) [34]. On the other hand, a highly reversible switching of electrical polarization in $\mathrm{TbMn}_{2} \mathrm{O}_{5}$ crystals can be achieved by using relatively low magnetic field of $2 \mathrm{~T}$ [33]. However, little interest has been paid to their magnetocaloric properties [19,20]. More recently, a large rotating MCE was reported in the $\mathrm{HoMn}_{2} \mathrm{O}_{5}$ single crystal at low temperatures [19], opening the way for the implementation of compact, simplified, and efficient magnetic refrigerators. On the basis of the rotating MCE observed in $\mathrm{HoMn}_{2} \mathrm{O}_{5}$, a new concept for the liquefaction of the helium and hydrogen was also proposed [19].

The multiferroics $\mathrm{RMn}_{2} \mathrm{O}_{5}(\mathrm{R}=$ rare earth) are insulators displaying an orthorhombic structure (Pbam) composed of $\mathrm{Mn}^{4+} \mathrm{O}_{6}$ octahedral and $\mathrm{Mn}^{3+} \mathrm{O}_{5}$ pyramidal units (see Figure 12) [31-36]. The octahedra share edges to form chains along the c-axis. The formed chains are linked by pairs of pyramids within the ab-plane. The interaction between $\mathrm{Mn}^{4+}, \mathrm{Mn}^{3+}$, and rare earth $\mathrm{R}^{3+}$ ions magnetic moments lead to a pronounced magnetic frustration resulting in complex magnetic and electric responses [31-36]. Usually, the $\mathrm{RMn}_{2} \mathrm{O}_{5}$ compounds present various phase transitions at low temperatures below $50 \mathrm{~K}$. Around $T_{\mathrm{N} 1}=45 \mathrm{~K}$, an incommensurate antiferromagnetic ordering of the $\mathrm{Mn}^{3+} / \mathrm{Mn}^{4+}$ magnetic moments takes place. This transition coincides with the appearance of a spontaneous electric polarization that occurs slightly down to $T_{\mathrm{N} 1}$ around $T_{C}=38 \mathrm{~K}$. The AFM ordering of $\mathrm{Mn}^{3+} / \mathrm{Mn}^{4+}$ spins transforms into a commensurate state at $T_{L}=33 \mathrm{~K}$ (lock-in temperature) and becomes again incommensurate around $T_{\mathrm{N} 2}=20 \mathrm{~K}$ [31-36]. The $\mathrm{R}^{3+}$ spins usually order below $15 \mathrm{~K}$ [31-36].

Until today, only the magnetocaloric properties of $\mathrm{HoMn}_{2} \mathrm{O}_{5}$ and $\mathrm{TbMn}_{2} \mathrm{O}_{5}$ single crystals (Figures 13-17) have been reported by Balli et al. [19,20]. The $\mathrm{HoMn}_{2} \mathrm{O}_{5}$ compound unveils a giant magnetic anisotropy (Figure 13) with the easy, intermediate, and hard crystallographic axes along the $\mathrm{b}-, \mathrm{a}-$, and c-orientations [19]. According to magnetization data, the $\mathrm{Ho}^{3+}$ magnetic moments were found to order around $10 \mathrm{~K}$, whereas the phase transitions involving the Mn-sublattice are not clearly visible from thermomagnetic curves because of the large magnetic moment of $\mathrm{Ho}^{3+}$ that overshadows the weak magnetization resulting from the Mn moments [19]. As reported in Balli et al. [19], the inverse magnetic susceptibility at high temperatures indicates antiferromagnetic interactions along the $c$ and a axes while a weak antiferromagnetic order or a paramagnetic disorder of $\mathrm{Ho}^{3+}$ moments is shown by 
$\mathrm{HoMn}_{2} \mathrm{O}_{5}$ along the easy-axis $\mathrm{b}$. This is in good agreement with early reported neutron diffraction data by Blake et al. [32]. Magnetocaloric properties of the $\mathrm{HoMn}_{2} \mathrm{O}_{5}$ single crystal [19] have been reported in terms of entropy and adiabatic temperature changes (Figures 14, 15a and 17). Along the easy-axis $\mathrm{b}$, the maximum isothermal entropy change was found to be 3.5 and $13.1 \mathrm{~J} / \mathrm{kg} \mathrm{K}$ in magnetic field changes of 2 and $7 \mathrm{~T}$, respectively. For the intermediate a-axis, $-\Delta S_{\max }$ reaches only $5 \mathrm{~J} / \mathrm{kg} \mathrm{K}$ under $7 \mathrm{~T}$ [19]. Following the hard-axis c, the resulting MCE is much lower even under high magnetic fields (Figure 15a). The associated refrigerant capacities were found to be 334, 157.5, and $44 \mathrm{~J} / \mathrm{Kg}$ under a magnetic field of $7 \mathrm{~T}$ parallel to the $\mathrm{b}$, $\mathrm{a}$, and $\mathrm{c}$ axes, respectively [19]. This can be mainly explained by the gigantic magnetocrystalline anisotropy shown by $\mathrm{HoMn}_{2} \mathrm{O}_{5}$ single crystals as plotted in Figure 13 . At $2 \mathrm{~K}$, the magnetization under magnetic field of $7 \mathrm{~T}$ applied along the easy-axis is $124 \mathrm{Am}^{2} / \mathrm{kg}$ and only $34 \mathrm{Am}^{2} / \mathrm{kg}$ for $\mathrm{H} / / \mathrm{c}$ [19]. Taking advantage of the anisotropic MCE shown by $\mathrm{HoMn}_{2} \mathrm{O}_{5}$ (Figure 15a) a large rotating magnetocaloric effect was also reported by Balli et al. [19]. By rotating the $\mathrm{HoMn}_{2} \mathrm{O}_{5}$ single crystal in constant magnetic field of $7 \mathrm{~T}$ around its a-axis, the resulting entropy change reaches a maximum value of $12.43 \mathrm{~J} / \mathrm{kg} \mathrm{K}$, being much larger that the rotating entropy change reported in $\mathrm{TbMnO}_{3}$ [21] and $\mathrm{TmMnO}_{3}$ [23], but lower if compared with the orthorhombic $\mathrm{DyMnO}_{3}$ single crystal [24] discussed above. On the other hand, the associated rotating adiabatic temperature change $(6.5 \mathrm{~K}$ in $7 \mathrm{~T})$ is about two times lower than that exhibited by o-DyMnO $3(11 \mathrm{~K}$ in $7 \mathrm{~T})$. This is mainly due to the largest magnetocrystalline anisotropy of the orthorhombic $\mathrm{DyMnO}_{3}$ as well as the enhancement of its magnetization along the easy-axis $\left(170 \mathrm{Am}^{2} / \mathrm{kg}\right)[24]$.

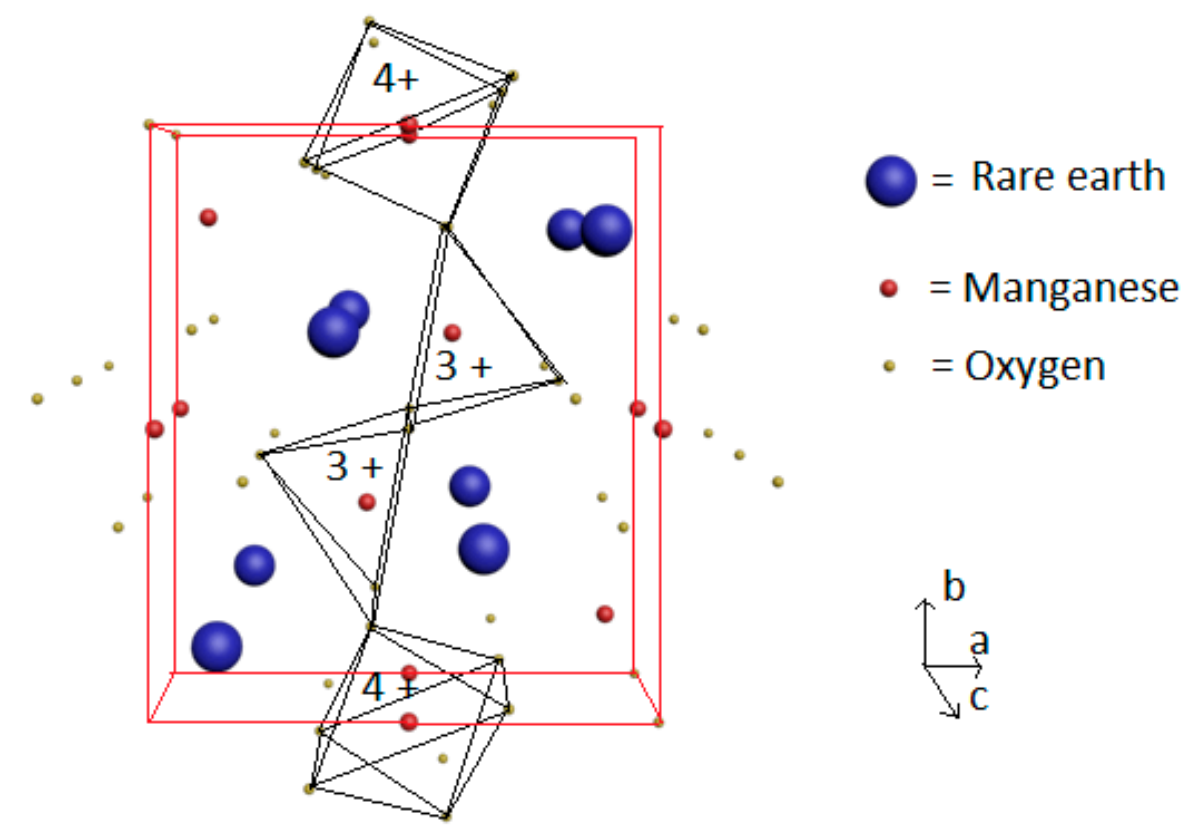

Figure 12. $\mathrm{RMn}_{2} \mathrm{O}_{5}$ orthorhombic structure. Each $\mathrm{Mn}^{3+}$ (red) is encased in the oxygens's (grey) pyramid while $\mathrm{Mn}^{4+}$ ions (red) are encased in the oxygens's octaedra. 


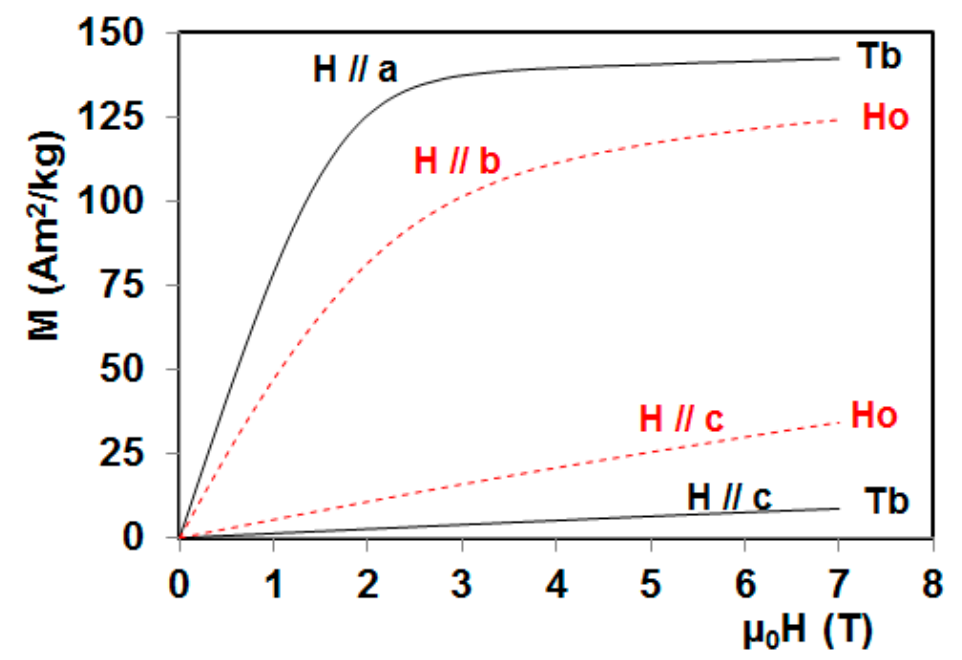

Figure 13. Magnetic isotherms at $2 \mathrm{~K}$ of $\mathrm{RMn}_{2} \mathrm{O}_{5}(\mathrm{R}=\mathrm{Ho}$ and $\mathrm{Tb})$ single crystals along their easy- and hard-axes $[19,20]$.

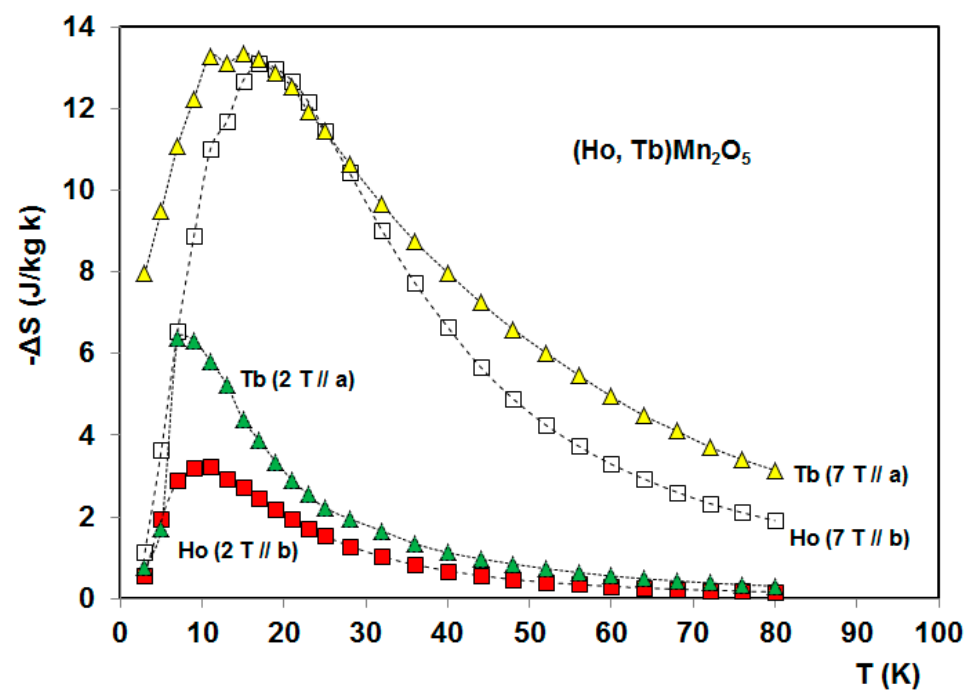

Figure 14. A comparison between entropy changes of $\mathrm{RMn}_{2} \mathrm{O}_{5}(\mathrm{R}=\mathrm{Ho}$ and $\mathrm{Tb}$ ) single crystals under relatively low (2 T) and high (7 T) magnetic fields applied along their easy-axes [19,20].
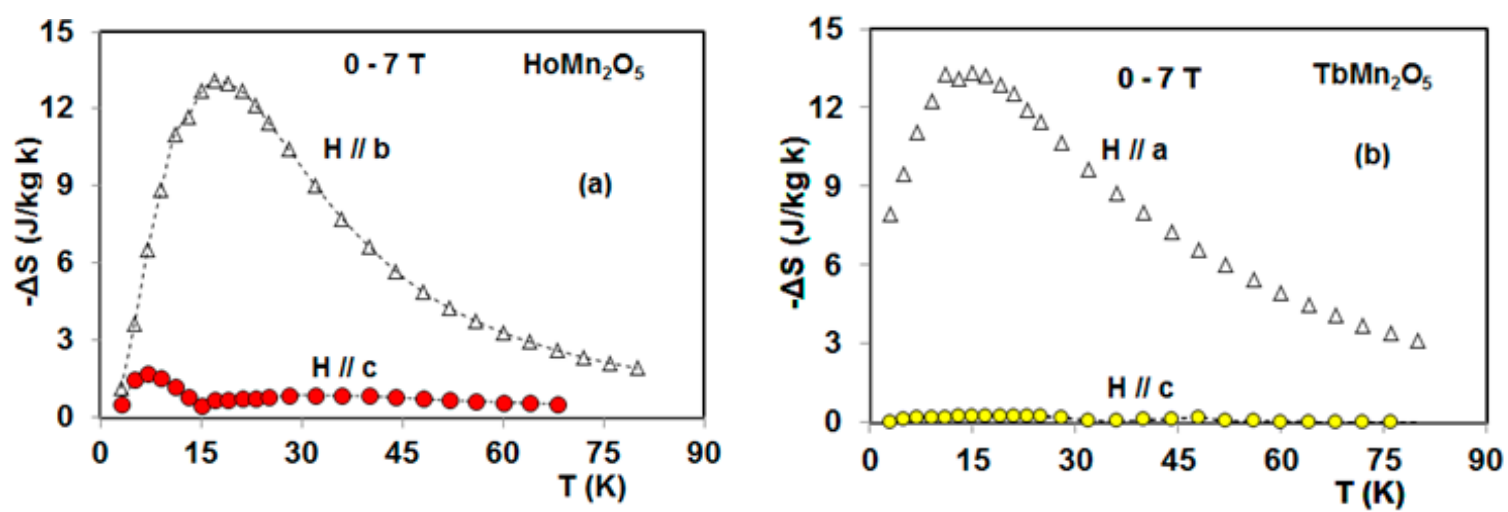

Figure 15. Isothermal entropy change of $\mathrm{HoMn}_{2} \mathrm{O}_{5}(\mathbf{a})$ and $\mathrm{TbMn}_{2} \mathrm{O}_{5}$ (b) single crystals under a magnetic field change of $7 \mathrm{~T}$ applied along their easy- and hard-axes $[19,20]$. 


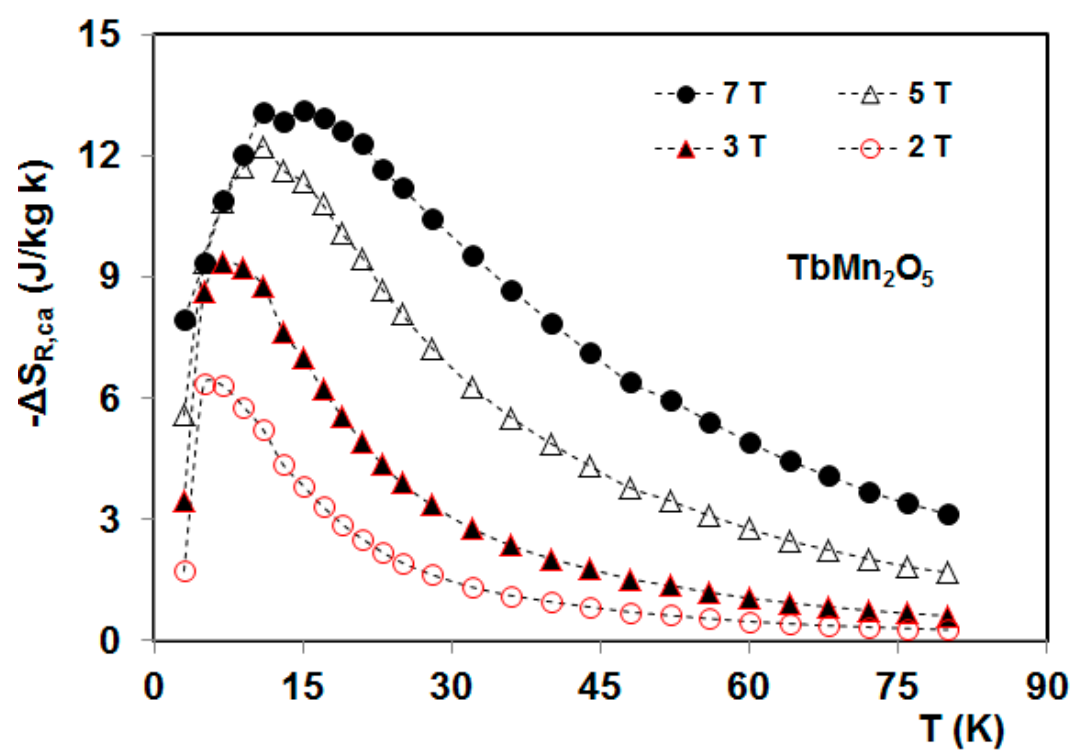

Figure 16. Rotating entropy change as a function of temperature for the single crystal $\mathrm{TbMn}_{2} \mathrm{O}_{5}$ in several constant magnetic fields, initially parallel to the c-axis [20].

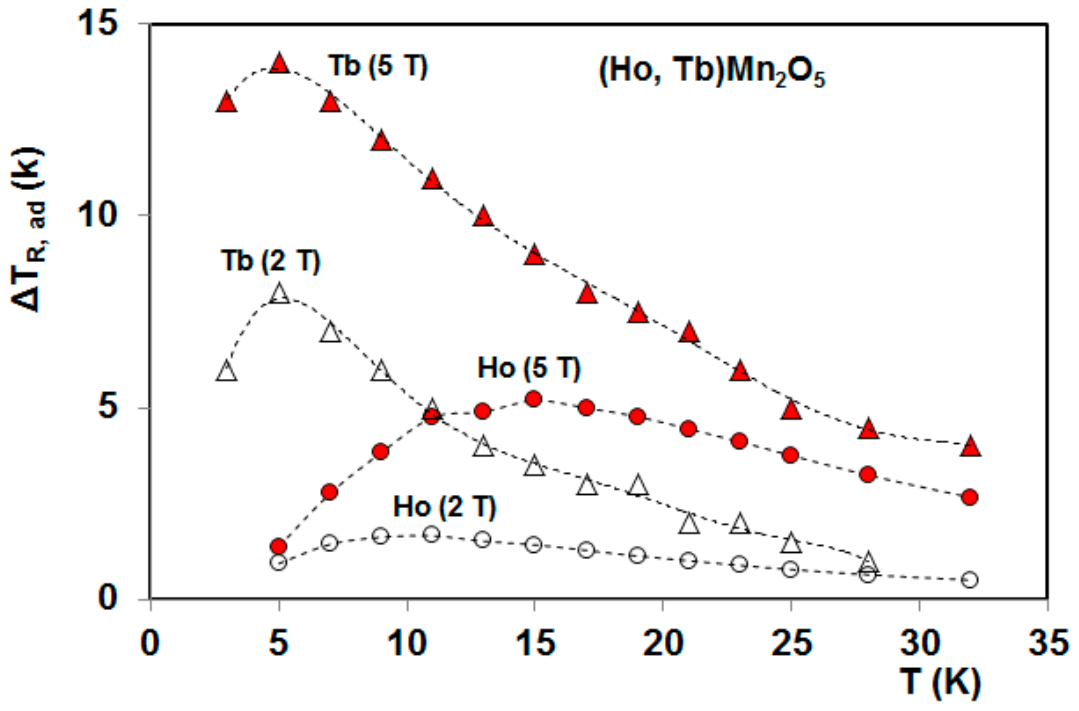

Figure 17. Rotating adiabatic temperature change as a function of temperature for $\mathrm{RMn}_{2} \mathrm{O}_{5}(\mathrm{R}=\mathrm{Ho}$ and $\mathrm{Tb}$ ) single crystals in constant magnetic fields of 2 and $5 \mathrm{~T}[19,20]$. The crystals are rotated by an angle of $90^{\circ}$ around their intermediate axes with magnetic fields initially parallel to the hard-axis.

In a following paper, the magnetocaloric properties of the $\mathrm{TbMn}_{2} \mathrm{O}_{5}$ single crystal were also reported by Balli et al. [20]. Thermomagnetic curves unveil clear features around 5 and $36 \mathrm{~K}$ corresponding to the ordering point of $\mathrm{Tb}^{3+}$ magnetic moment and the onset of ferroelectric order, respectively [33]. However, additional transitions which occur at $24 \mathrm{~K}$ and $40 \mathrm{~K}$ can be clearly seen in specific heat measurements [33,34] but are not visible in the thermomagnetic curves reported in Ref. [20]. The $24 \mathrm{~K}$ and $40 \mathrm{~K}$ transitions were attributed to the $\mathrm{Mn}^{3+} / \mathrm{Mn}^{4+}$ spins reorientation and to the long range antiferromagnetic order of the $\mathrm{Mn}^{3+} / \mathrm{Mn}^{4+}$ spins, respectively. The magnetization data also reveal strong antiferromagnetic interactions along the $b$ and $c$ axes, whereas ferromagnetic exchanges are further associated with the a-axis [20]. The isothermal magnetization curves $\mathrm{M}\left(\mu_{0} \mathrm{H}\right)$ measured at $2 \mathrm{~K}$ (Figure 13), demonstrate the presence of a large magnetocrystalline anisotropy, where the easy and hard magnetization directions are parallel to the a and c axes, respectively. The gigantic 
magnetocrystalline anisotropy is mainly attributed to the large spin-orbit interplay of the $\mathrm{Tb}$ moments in $\mathrm{TbMn}_{2} \mathrm{O}_{5}$ single crystals [33,34]. Also, the magnetic exchange interactions between $\mathrm{Tb}^{3+}, \mathrm{Mn}^{3+}$, and $\mathrm{Mn}^{4+}$ moments in $\mathrm{TbMn}_{2} \mathrm{O}_{5}$ cannot all be satisfied simultaneously, leading to a geometrically frustrated magnetic system. The magnetization saturation can be clearly seen for a magnetic field above $2 \mathrm{~T}$ applied along the a-axis (Figure 13). The corresponding saturation magnetic moment is $140 \mathrm{Am}^{2} / \mathrm{kg}(8.75 \mu \mathrm{B} / \mathrm{f} . \mathrm{u})$ which is about $52 \%$ of that calculated $\left(268.8 \mathrm{Am}^{2} / \mathrm{kg}\right)$ when considering a parallel configuration of all the magnetic moments of $\mathrm{Tb}^{3+}\left(9 \mu_{B}\right), \mathrm{Mn}^{4+}\left(3.8 \mu_{B}\right)$ and $\mathrm{Mn}^{3+}\left(4 \mu_{B}\right)$ [20]. Additionally, the resulting magnetization saturation is very close to the $\mathrm{Tb}^{3+}$ magnetic moment $(9 \mu \mathrm{B})$. This means that the $\mathrm{Tb}^{3+}$ magnetic moments can be completely aligned under sufficiently high magnetic fields applied along the easy-axis, considering the weak contribution of $\mathrm{Mn}$ spins to the total magnetization [31-36]. Moreover, the magnetization at $7 \mathrm{~T}$ decreases by about $94 \%$ when the magnetic field direction is changed from the easy-axis to the hard-axis. This leads to a giant anisotropy of the $\mathrm{MCE}$ (Figure 15b) in $\mathrm{TbMn}_{2} \mathrm{O}_{5}$ single crystals [20]. For example, the maximum value of $-\Delta S$ along the easy axis in a field of $7 \mathrm{~T}$ is about 63 times larger than that along the hard-orientation.

The magnetic field variation from 0 to 2 and 0 to $7 \mathrm{~T}$ yields to a maximum entropy change of 6.4 and $13.35 \mathrm{~J} / \mathrm{kg} \mathrm{K}$, for $\mathrm{H} / /$ a (Figure 14) while it is only 0.33 and $3 \mathrm{~J} / \mathrm{kg} \mathrm{K}$ for $\mathrm{H} / / \mathrm{b}$, respectively [20]. The resulting entropy change along the hard-axis $\mathrm{c}$ was found to be practically zero [20]. Considering the case in which the disordered magnetic phase of $\mathrm{Tb}^{3+}$ ions is changed to a completely ordered phase, the theoretical limit of the resulting entropy change is given by $\Delta S_{\text {Limt }}=\mathrm{R}^{*} \mathrm{Ln}(2 \mathrm{~J}+1)=61.18 \mathrm{~J} / \mathrm{kg} \mathrm{K}$ (here, $\mathrm{R}$ is the universal gas constant and $\mathrm{J}$ is the angular momentum quantum number). As for $\mathrm{Tb}^{3+}$, $\mathrm{J}$ was assumed to be 6 for the $\mathrm{TbMn}_{2} \mathrm{O}_{5}$ single crystal. For a magnetic field variation from 0 to $7 \mathrm{~T}$ along the ordering axis of $\mathrm{Tb}^{3+}$ moments (a-axis), only $22 \%$ of $\Delta S_{\text {Limt }}$ can be obtained upon saturation of the magnetization, revealing that entropy changes larger than $13.35 \mathrm{~J} / \mathrm{kg} \mathrm{K}$ may be reached under intense external magnetic fields.

The $\mathrm{TbMn}_{2} \mathrm{O}_{5}$ refrigerant capacity was also reported by Balli et al. [20]. With increasing field, the $\mathrm{RC}$ was found to increase almost linearly with a rate of about $79 \mathrm{~J} / \mathrm{kg} \mathrm{T}, 8 \mathrm{~J} / \mathrm{kg} \mathrm{T}$ for H/ $/ \mathrm{a}$ and $\mathrm{H} / / \mathrm{b}$, respectively. Along the hard-direction, the $\mathrm{RC}$ is negligible. When changing the magnetic field from 0 to $7 \mathrm{~T}$, the RC reaches values of $480 \mathrm{~J} / \mathrm{kg}, 47 \mathrm{~J} / \mathrm{kg}$ and only about $4 \mathrm{~J} / \mathrm{kg}$ along the a, $\mathrm{b}$, and $\mathrm{c}$ axes, respectively. Considering magnetocaloric oxides with similar working temperature range, the magnetocaloric properties of $\mathrm{TbMnO}_{3}$ were investigated and reported in [21]. Although the $\mathrm{TbMnO}_{3}$ and $\mathrm{TbMn}_{2} \mathrm{O}_{5}$ single crystals contain the same rare earth element $\left(\mathrm{Tb}^{3+}\right)$ and present a similar magnetization saturation (about $140 \mathrm{Am}^{2} / \mathrm{kg}$ ), it was found that the maximum isothermal entropy change under $7 \mathrm{~T}$ along the easy-axis a for $\mathrm{TbMnO}_{3}$ is larger $(18 \mathrm{~J} / \mathrm{kg} \mathrm{K})$ than that exhibited by $\mathrm{TbMn}_{2} \mathrm{O}_{5}$ (13.35 J/kg K). However, the RC for $\mathrm{TbMn}_{2} \mathrm{O}_{5}$ is much larger than that for $\mathrm{TbMnO}_{3}(390 \mathrm{~J} / \mathrm{kg}$ for $7 \mathrm{~T} / / \mathrm{a})$. Theses observed deviations originate mainly from the significant difference in their magnetic structures. In fact, the antiferromagnetic ground state is not quite stable in $\mathrm{TbMnO}_{3}$ against applied magnetic field along the easy-axis a [21]. At low temperatures, the spiral magnetic structure of $\mathrm{Tb}^{3+}$ and $\mathrm{Mn}^{3+}$ ions in $\mathrm{TbMnO}_{3}$ enables a first-order magnetic transition of $\mathrm{Tb}^{3+}$ moments from the antiferromagnetic state to the ferromagnetic phase to be easily induced. Such metamagnetic-like transformation means that the magnetization can rapidly be changed with varying magnetic field leading to a large magnetic entropy change. In contrast to $\mathrm{TbMnO}_{3}$, the magnetic phase transition associated with the magnetic moments ordering of $\mathrm{Tb}^{3+}$ in the single crystal $\mathrm{TbMn}_{2} \mathrm{O}_{5}$ shows a second-order character, as determined from Arrott plots [97] (not shown here). This makes the magnetic transition broader, leading to a large RC in $\mathrm{TbMn}_{2} \mathrm{O}_{5}$ single crystals. On the other hand, the $\mathrm{RC}$ of the $\mathrm{TbMn}_{2} \mathrm{O}_{5}$ single crystal $(314 \mathrm{~J} / \mathrm{kg}$ for $5 \mathrm{~T})$ along the easy-axis is much larger than that found in the $\mathrm{HoMn}_{2} \mathrm{O}_{5}$ oxide (334 J/kg for $7 \mathrm{~T}$ ) [19] and even in some well-known intermetallics such as $\mathrm{ErRu}_{2} \mathrm{Si}_{2}$ (196.5 J/kg for $\left.5 \mathrm{~T}\right)$ [92], DySb (144 J/kg for 5 T) [98], and $\mathrm{ErMn}_{2} \mathrm{Si}_{2}$ (273 J/kg for 5 T) [99].

In addition to a large standard MCE resulting from the magnetization-demagnetization process (Figure 14), the $\mathrm{TbMn}_{2} \mathrm{O}_{5}$ compound also exhibits a giant rotating MCE (Figures 16 and 17) that can be obtained by spinning its single crystals in a constant magnetic field within the ac-plane (around 
its b-axis) [20,100]. For a constant magnetic field of 2 and $7 \mathrm{~T}$ applied in the ac-plane, the rotation of $\mathrm{TbMn}_{2} \mathrm{O}_{5}$ single crystals around the b-axis, enables maximum entropy changes of 6.4 and $13.14 \mathrm{~J} / \mathrm{kg} \mathrm{K}$, respectively, to be induced, being much larger than the rotating entropy change reported in some known materials such as $\mathrm{TbMnO}_{3}(8.2 \mathrm{~J} / \mathrm{kg} \mathrm{K})$ [21]. The corresponding RC was found to be $476 \mathrm{~J} / \mathrm{kg}$ under $7 \mathrm{~T}$ instead of only $304 \mathrm{~J} / \mathrm{kg}$ for $\mathrm{TbMnO}_{3}$ [21]. On the other hand, at low magnetic fields $\Delta S_{R}$ shown by $\mathrm{TbMn}_{2} \mathrm{O}_{5}(6.4 \mathrm{~J} / \mathrm{kg} \mathrm{K}$ at $2 \mathrm{~T})$ is two and three times larger than that exhibited by $\mathrm{HoMn}_{2} \mathrm{O}_{5}$ [19] and $\mathrm{TbMnO}_{3}$ [21] single crystals, respectively. This is mainly due to the giant magnetic anisotropy in $\mathrm{TbMn}_{2} \mathrm{O}_{5}$ as well as the possibility to reach the saturation state under relatively low magnetic fields giving rise to large magnetization along its easy-axis (Figure 13) [20]. Additionally, the RMCE was also investigated in $\mathrm{TbMn}_{2} \mathrm{O}_{5}$ in terms of the adiabatic temperature change (Figure 17). In a constant magnetic field of $2 \mathrm{~T}$, the rotating $\Delta T_{a d}$ reaches a maximum value $(8 \mathrm{~K})$ that is six times higher than that presented by $\mathrm{TbMnO}_{3}$ [21]. The rotating adiabatic temperature change shown by $\mathrm{TbMn}_{2} \mathrm{O}_{5}$ also largely exceeds that presented by the $\mathrm{HoMn}_{2} \mathrm{O}_{5}$ single crystal (Figure 17). The enhancement of $\Delta T_{a d}$ in $\mathrm{TbMn}_{2} \mathrm{O}_{5}$ is partly caused by its low specific heat [34] that is about three times lower when compared with $\mathrm{TbMnO}_{3}$ [37] and $\mathrm{HoMn}_{2} \mathrm{O}_{5}$ [34] single crystals.

\section{Conclusions}

In this report we reviewed the magnetic and magnetocaloric properties of $\mathrm{RMnO}_{3}$ and $\mathrm{RMn}_{2} \mathrm{O}_{5}$ multiferroic single crystals. In both families of materials, the competition between different magnetic exchange interactions involving $\mathrm{Mn}^{3+}, \mathrm{Mn}^{4+}$ and $\mathrm{R}^{3+}$ sublattices results in several phase transitions usually occurring below $100 \mathrm{~K}$. However, only the magnetic phase transition associated with the ordering of $\mathrm{R}^{3+}$ magnetic moments at temperatures usually below $20 \mathrm{~K}$ contributes to the magnetocaloric effect. The application of sufficiently high magnetic fields along the easy-axis enables large thermal effects to be generated around the ordering point of the rare earth elements $(\sim 10 \mathrm{~K})$. In some compounds such as orthorhombic $\mathrm{DyMnO}_{3}$ and $\mathrm{TbMn}_{2} \mathrm{O}_{5}$ single crystals, relatively low magnetic fields are required to achieve a large MCE. This is of great importance from economical and practical points of view since the needed fields can be provided by permanent magnets. Additionally, most of $\mathrm{RMnO}_{3}$ and $\mathrm{RMn}_{2} \mathrm{O}_{5}$ single crystals unveil a gigantic anisotropy of the magnetocaloric effect which means that additional thermal effects can also be obtained by rotating them between the hard- and easy-directions in constant magnetic fields. This could open the way for the design of more compact, efficient, and simplified magnetocaloric devices. On the other hand, the strong magnetoelectric coupling usually observed in these compounds offers an additional degree of freedom since the MCE could, for example, be tailored by an electric field through the manipulation of the ferroelectric order.

All these features combined with the insulating character as well as the high chemical stability (in comparison with intermetallics) render $\mathrm{RMnO}_{3}$ and $\mathrm{RMn}_{2} \mathrm{O}_{5}$ multiferroics more attractive particularly in cryomagnetocaloric refrigerators.

Acknowledgments: The authors thank M. Castonguay, S. Pelletier and B. Rivard for technical support. We acknowledge the financial support from NSERC (Canada), FQRNT (Québec), CFI, CIFAR, Canada First Research Excellence Fund (Apogée Canada) and the Université de Sherbrooke. M. Balli would like to thank $\mathrm{S}$. Mansouri for the fruitful discussion regarding the magnetoelectric interplay in multiferroic $\mathrm{RMnO}_{3}$ and $\mathrm{RMn}_{2} \mathrm{O}_{5}$ compounds.

Author Contributions: Mohamed Balli conceived the work prepared Figures and analyzed data, wrote the paper; Benoit Roberge prepared Figures and co-wrote the paper; Mohamed Balli, Benoit Reberge, Serge Jandl, and Patrick Fournier revised the paper.

Conflicts of Interest: The authors declare no conflict of interest. 


\section{References}

1. Gschneidner, K.A., Jr.; Pecharsky, V.K.; Tsokol, A.O. Recent developments in magnetocaloric materials. Rep. Prog. Phys. 2005, 68, 1479. [CrossRef]

2. Moya, X.; Kar-Narayan, S.; Mathur, N.D. Caloric materials near ferroic phase transitions. Nat. Mater. 2014, 13, 439-450. [CrossRef] [PubMed]

3. Pecharsky, V.K.; Gschneidner, K.A., Jr. Giant Magnetocaloric Effect in $\mathrm{Gd}_{5} \mathrm{Ge}_{2} \mathrm{Si}_{2}$. Phys. Rev. Lett. 1997, 78, 4494. [CrossRef]

4. Wada, H.; Tanabe, Y. Giant magnetocaloric effect of MnAs ${ }_{1-x} \mathrm{Sb}_{x}$. Appl. Phys. Lett. 2001, 79, 3302. [CrossRef]

5. Balli, M.; Fruchart, D.; Gignoux, D.; Dupuis, C.; Kedous-Lebouc, A.; Zach, R. Giant magnetocaloric effect in $\mathrm{Mn}_{1-\mathrm{x}}\left(\mathrm{Ti}_{0.5} \mathrm{~V}_{0.5}\right)_{\mathrm{x}} \mathrm{As}$ : Experiments and calculations. J. Appl. Phys. 2008, 103, 103908. [CrossRef]

6. Balli, M.; Fruchart, D.; Gignoux, D.; Tobola, J.; Hlil, E.K.; Wolfers, P.; Zach, R. Magnetocaloric effect in ternary metal phosphides $\left(\mathrm{Fe}_{1-\mathrm{x}} \mathrm{Ni}_{\mathrm{x}}\right)_{2}$ P. J. Magn. Magn. Mater. 2007, 316, 358-360. [CrossRef]

7. Tegus, O.; Brück, E.; Buschow, K.H.J.; De Boer, F.R. Transition-metal-based magnetic refrigerants for room-temperature applications. Nature 2002, 415, 150-152. [CrossRef] [PubMed]

8. Fujita, A.; Fujieda, S.; Hasegawa, Y.; Fukamichi, K. Itinerant-electron metamagnetic transition and large magnetocaloric effects in $\mathrm{La}\left(\mathrm{Fe}_{\mathrm{x}} \mathrm{Si}_{1-\mathrm{x}}\right)_{13}$ compounds and their hydrides. Phys. Rev. B 2003, 67, 104416. [CrossRef]

9. Hu, F.X.; Shen, B.G.; Sun, J.R.; Wang, G.J.; Cheng, Z.H. Very large magnetic entropy change near room temperature in $\mathrm{LaFe}_{11.2} \mathrm{Co}_{0.7} \mathrm{Si}_{1.1}$. Appl. Phys. Lett. 2002, 80, 826-828. [CrossRef]

10. Balli, M.; Fruchart, D.; Gignoux, D. The $\mathrm{LaFe}_{11.2} \mathrm{Co}_{0.7} \mathrm{Si}_{1.1} \mathrm{C}_{\mathrm{x}}$ carbides for magnetic refrigeration close to room temperature. Appl. Phys. Lett. 2008, 92, 232505. [CrossRef]

11. Balli, M.; Fruchart, D.; Gignoux, D. Optimization of $\mathrm{La}(\mathrm{Fe}, \mathrm{Co})_{13-\mathrm{x}} \mathrm{Si}_{\mathrm{x}}$ based compounds for magnetic refrigeration. J. Phys. Condens. Matter 2007, 19, 236230. [CrossRef]

12. Phan, M.H.; Yu, S.C. Review of the magnetocaloric effect in manganite materials. J. Magn. Magn. Mat 2007, 308, 325-340. [CrossRef]

13. Balli, M.; Fruchart, D.; Gignoux, D. Effect of Ni substitution on the magnetic and magnetocaloric properties of the Dy $\left(\mathrm{Co}_{1-\mathrm{x}} \mathrm{Ni}_{\mathrm{x}}\right)_{2}$ Laves phase. J. Phys. D Appl. Phys. 2007, 40, 7601. [CrossRef]

14. Balli, M.; Fruchart, D.; Gignoux, D.; Hlil, E.K.; Miraglia, S.; Wolfers, P. Gd $\mathrm{d}_{1-\mathrm{x}} \mathrm{Tb}_{\mathrm{x}}$ alloys for Ericsson-like magnetic refrigeration cycles. J. Alloys Compd. 2007, 442, 129-131. [CrossRef]

15. Sari, O.; Balli, M. From conventional to magnetic refrigerator technology. Int. J. Refrig. 2014, 37, 8-15. [CrossRef]

16. Balli, M.; Sari, O.; Mahmed, C.; Besson, C.; Bonhote, P.; Duc, D.; Forchelet, J. A pre-industrial magnetic cooling system for room temperature application. Appl. Energy 2012, 98, 556-561. [CrossRef]

17. Zimm, C.; Jastrab, A.; Sternberg, A.; Pecharsky, V.; Gschneidner, K., Jr.; Osborne, M.; Anderson, I. Description and Performance of a Near-Room Temperature Magnetic Refrigerator. Adv. Cryog. Eng. 1998, 43, 1759-1766.

18. Barclay, J.; Oseen-Senda, K.; Skrzypkowski, M. Unique feature of liquefaction of hydrogen and natural gas using magnetic refrigeration. In Proceedings of 6th IIF-IIR International Conference on Magnetic Refrigeration, Victoria, BC, Canada, 7-10 September 2014.

19. Balli, M.; Jandl, S.; Fournier, P.; Gospodinov, M.M. Anisotropy-enhanced giant reversible rotating magnetocaloric effect in $\mathrm{HoMn}_{2} \mathrm{O}_{5}$ single crystals. Appl. Phys. Lett. 2014, 104, 232402. [CrossRef]

20. Balli, M.; Jandl, S.; Fournier, P.; Dimitrov, D.Z. Giant rotating magnetocaloric effect at low magnetic fields in multiferroic $\mathrm{TbMn}_{2} \mathrm{O}_{5}$ single crystals. Appl. Phys. Lett. 2016, 108, 102401. [CrossRef]

21. Jin, J.L.; Zhang, X.Q.; Li, G.K.; Cheng, Z.H.; Zheng, L.; Lu, Y. Giant anisotropy of magnetocaloric effect in $\mathrm{TbMnO}_{3}$ single crystals. Phys. Rev. B 2011, 83, 184431. [CrossRef]

22. Balli, M.; Jandl, S.; Fournier, P.; Mansouri, S.; Mukhin, A.; Ivanov, Y.V.; Balbashov, A.M. On the magnetocaloric effect in the multiferroic hexagonal $\mathrm{DyMnO}_{3}$ single crystals. J. Magn. Magn. Mat. 2015, 374, 252-257. [CrossRef]

23. Jin, J.L.; Zhang, X.Q.; Ge, H.; Cheng, Z.H. Rotating field entropy change in hexagonal $\mathrm{TmMnO}_{3}$ single crystal with anisotropic paramagnetic response. Phys. Rev. B 2012, 85, 214426. [CrossRef]

24. Balli, M.; Mansouri, S.; Jandl, S.; Fournier, P.; Dimitrov, D.Z. Large rotating magnetocaloric effect in the orthorhombic $\mathrm{DyMnO}_{3}$ single crystal. Solid. Stat. Commun. 2016, 239, 9-13. [CrossRef] 
25. Li, L.; Namiki, T.; Huo, D.; Qian, Z.; Nishimura, K. Two successive magnetic transitions induced large refrigerant capacity in HoPdIn compound. Appl. Phys. Lett. 2013, 103, 222405.

26. Midya, A.; Das, S.N.; Mandal, P.; Pandya, S.; Ganesan, V. Anisotropic magnetic properties and giant magnetocaloric effect in antiferromagnetic $\mathrm{RMnO}_{3}$ crystals $(\mathrm{R}=\mathrm{Dy}, \mathrm{Tb}, \mathrm{Ho}$, and $\mathrm{Yb}$ ). Phys. Rev. B 2011, 84, 235127. [CrossRef]

27. Balli, M.; Roberge, B.; Vermette, J.; Jandl, S.; Fournier, P.; Gospodinov, M.M. Magnetocaloric properties of the hexagonal $\mathrm{HoMnO}_{3}$ single crystal revisited. Physica B 2015, 478, 77-83. [CrossRef]

28. Balli, M.; Roberge, B.; Jandl, S.; Fournier, P.; Palstra, T.T.M.; Nugroho, A.A. Observation of large refrigerant capacity in the $\mathrm{HoVO}_{3}$ vanadate single crystal. J. Appl. Phys. 2015, 118, 073903. [CrossRef]

29. Matsumoto, K.; Kondo, T.; Yoshioka, S.; Kamiya, K.; Numazawa, T. Magnetic refrigerator for hydrogen liquefaction. J. Phys. Conf. Ser. 2009, 150, 012028. [CrossRef]

30. Numazawa, T.; Kamiya, K.; Utaki, T.; Matsumoto, K. Magnetic refrigerator for hydrogen liquefaction. Cryogenics 2014, 62, 185-192. [CrossRef]

31. Noda, Y.; Kimura, H.; Fukunaga, M.; Kobayashi, S.; Kagomiya, I.; Kohn, K. Magnetic and ferroelectric properties of multiferroic $\mathrm{RMn}_{2} \mathrm{O}_{5}$. J. Phys. Condens. Matter 2008, 20, 434206. [CrossRef]

32. Blake, G.R.; Chapon, L.C.; Radaelli, P.G.; Park, S.; Hur, N.; Cheong, S.W.; Rodriguez-Carvajal, J. Spin structure and magnetic frustration in multiferroic $\mathrm{RMn}_{2} \mathrm{O}_{5}(\mathrm{R}=\mathrm{Tb}, \mathrm{Ho}$, Dy). Phys. Rev. B 2005, 71, 214402. [CrossRef]

33. Hur, N.; Park, S.; Sharma, P.A.; Ahn, J.S.; Guha, S.; Cheong, S.W. Electric polarization reversal and memory in a multiferroic material induced by magnetic fields. Nature 2004, 429, 392-395. [CrossRef] [PubMed]

34. Hur, N.; Park, S.; Sharma, P.A.; Guha, S.; Cheong, S.W. Colossal Magnetodielectric Effects in $\mathrm{DyMn}_{2} \mathrm{O}_{5}$. Phys. Rev. Lett. 2004, 93, 107207. [CrossRef] [PubMed]

35. Mihailova, B.; Gospodinov, M.M.; Güttler, B.; Yen, F.; Litvinchuk, A.P.; Iliev, M.N. Temperature-dependent Raman spectra of $\mathrm{HoMn}_{2} \mathrm{O}_{5}$ and $\mathrm{TbMn}_{2} \mathrm{O}_{5}$. Phys. Rev. B 2005, 71, 172301. [CrossRef]

36. Tzankov, D.; Skumryev, V.; Aroyo, M.; Puźniak, R.; Kuz'min, M.D.; Mikhov, M. Magnetic anisotropy of multiferroic $\mathrm{HoMn}_{2} \mathrm{O}_{5}$ single crystal. Solid. Stat. Commun. 2008, 147, 212-216. [CrossRef]

37. Kimura, T.; Goto, T.; Shintani, H.; Ishizaka, K.; Arima, T.; Tokura, Y. Magnetic control of ferroelectric polarization. Nature 2003, 426, 55-58. [CrossRef] [PubMed]

38. Lottermoser, T.; Lonkai, T.; Amann, U.; Hohlwein, D.; Ihringer, J.; Fiebig, M. Magnetic phase control by an electric field. Nature 2004, 430, 541-544. [CrossRef] [PubMed]

39. Goto, T.; Kimura, T.; Lawes, G.; Ramirez, A.P.; Tokura, Y. Ferroelectricity and Giant Magnetocapacitance in Perovskite Rare-Earth Manganites. Phys. Rev. Lett. 2004, 92, 257201. [CrossRef] [PubMed]

40. Prokhnenko, O.; Feyerherm, R.; Dudzik, E.; Landsgesell, S.; Aliouane, N.; Chapon, L.C.; Argyriou, D.N. Enhanced Ferroelectric Polarization by Induced Dy Spin Order in Multiferroic DyMnO 3 . Phys. Rev. Lett. 2007, 98, 057206. [CrossRef] [PubMed]

41. Lee, J.H.; Murugavel, P.; Lee, D.; Noh, T.W.; Jo, Y.; Jung, M.H.; Jang, K.H.; Park, J.G. Multiferroic properties of epitaxially stabilized hexagonal $\mathrm{DyMnO}_{3}$ thin films. Appl. Phys. Lett. 2007, 90, 012903. [CrossRef]

42. Tishin, A.M.; Spichkin, Y.L. The Magnetocaloric Effect and Its Applications; IOP Publishing Ltd.: London, UK, 2003.

43. Balli, M.; Mahmed, C.; Bonhote, P.; Sari, O. On the magnetic forces in magnetic cooling machines: Numerical calculations and experimental investigations. IEEE Trans. Magn. 2011, 47, 3383-3386. [CrossRef]

44. Balli, M.; Fruchart, D.; Zach, R. Negative and conventional magnetocaloric effects of a MnRhAs single crystal. J. Appl. Phys. 2014, 115, 203909. [CrossRef]

45. Balli, M.; Fruchart, D.; Gignoux, D.; Zach, R. The "colossal” magnetocaloric effect in $\mathrm{Mn}_{1-\mathrm{x}} \mathrm{Fe}_{\mathrm{x}}$ As: What are we really measuring? Appl. Phys. Lett. 2009, 95, 072509. [CrossRef]

46. Balli, M.; Sari, O.; Fruchart, D.; Forchelet, J. Influence of the materials magnetic state on the accurate determination of the magnetocaloric effect. Eur. Phys. J. Web Conf. 2012, 29, 00005. [CrossRef]

47. Gschneidner, K.A., Jr.; Pecharsky, V.K. Magnetocaloric Materials. Annu. Rev. Mater. Sci. 2000, 30, $387-429$. [CrossRef]

48. Niknia, I.; Trevizoli, P.V.; Govindappa, P.; Campbell, O.; Christiaanse, T.V.; Teyber, R.; Rowe, A. A material screening technique for optimum performance of an AMR. In Proceedings of the Seventh IIF-IIR International Conference on Magnetic Refrigeration at Room Temperature, Thermag VII, Torino, Italy, 11-14 September 2016. 
49. Lee, S.; Pirogov, A.; Han, J.H.; Park, J.G.; Hoshikawa, A.; Kamiyama, T. Direct observation of a coupling between spin, lattice and electric dipole moment in multiferroic $\mathrm{YMnO}_{3}$. Phys. Rev. B 2005, 71, 180413. [CrossRef]

50. Bary'achtar, V.G.; L'vov, V.A.; Jablonskii, D.A. Theory of inhomogeneous magnetoelectric effect. Sov. JETP Lett. 1983, 37, 565-567.

51. Stefanovskii, E.P.; Jablonskii, D.A. Theory of electrical polarization of multisublattice orthorhombic antiferromagnets with a double-exchange superlattice. Sov. J. Low Temp. Phys. 1986, 12, 478-480.

52. Mostovoy, M. Ferroelectricity in Spiral Magnets. Phys. Rev. Lett. 2006, 96, 067601. [CrossRef] [PubMed]

53. Matsumoto, G. Study of $\left(\mathrm{La}_{1-\mathrm{x}} \mathrm{Ca}_{\mathrm{x}}\right) \mathrm{MnO}_{3}$. I. Magnetic Structure of LaMnO 3 . J. Phys. Soc. Jpn. 1970, 29, 606-615. [CrossRef]

54. Wollan, E.O.; Koehler, W.C. Neutron Diffraction Study of the Magnetic Properties of the Series of Perovskite-Type Compounds [(1-x)La, xCa] $\mathrm{MnO}_{3}$. Phys. Rev. 1955, 100, 545. [CrossRef]

55. Katsura, H.; Nagaosa, N.; Balatsky, V. Spin current and magnetoelectric effect in noncollinear magnets. Phys. Rev. Lett. 2005, 95, 057205. [CrossRef] [PubMed]

56. Sergienko, I.A.; Dagotto, E. Role of the Dzyaloshinskii-Moriya interaction in multiferroic perovskites. Phys. Rev. B 2006, 73, 094434. [CrossRef]

57. Dzyaloshinskii, I. Theory of Helicoidal Structures in Antiferromagnets. I. Nonmetals. Sov. Phys. JETP 1964, 19, 960-971.

58. Moriya, T. Anisotropic Superexchange Interaction and Weak Ferromagnetism. Phys. Rev. 1960, 120, 91-98. [CrossRef]

59. Kenzelmann, M.; Harris, A.B.; Jonas, S.; Broholm, C.; Schefer, J.; Kim, S.B.; Zhang, C.L.; Cheong, S.-W.; Vajk, O.P.; Lynn, J.W. Magnetic Inversion Symmetry Breaking and Ferroelectricity in $\mathrm{TbMnO}_{3}$. Phys. Rev. Lett. 2005, 95, 087206. [CrossRef] [PubMed]

60. Kimura, T.; Ishihara, S.; Shintani, H.; Arima, T.; Takahashi, K.T.; Ishizaka, K.; Tokura, Y. Distorted perovskite with e1g configuration as a frustrated spin system. Phys. Rev. B 2003, 68, 060403(R). [CrossRef]

61. Fukunaga, M.; Noda, Y. Classification and interpretation of the polarization of multiferroic $\mathrm{RMn}_{2} \mathrm{O}_{5}$. J. Phys. Soc. Jpn. 2010, 79, 054705. [CrossRef]

62. Xiang, H.J.; Wei, S.H.; Whangbo, M.H.; Da Silva, J.L. Spin-Orbit Coupling and Ion Displacements in Multiferroic $\mathrm{TbMnO}_{3}$. Phys. Rev. Lett. 2008, 101, 037209. [CrossRef] [PubMed]

63. Lee, J.H.; Jang, H.M. Modulated spin structure responsible for the magnetic-field-induced polarization switching in multiferroic TbMn $2 \mathrm{O}_{5}$. Phys. Rev. B 2005, 91, 014403. [CrossRef]

64. Oh, Y.S.; Jeon, B.G.; Haam, S.Y.; Park, S.; Correa, V.F.; Lacerda, A.H.; Cheong, S.-W.; Jeon, G.S.; Kim, K.H. Strong magnetoelastic effect on the magnetoelectric phenomena of $\mathrm{TbMn}_{2} \mathrm{O}_{5}$. Phys. Rev. B 2011, 83, 060405(R). [CrossRef]

65. Harikrishnan, S.; Rößler, S.; Kumar, C.N.; Bhat, H.L.; Rößler, U.K.; Wirth, S.; Steglich, F.; Elizabeth, S. Phase transitions and rare-earth magnetism in hexagonal and orthorhombic $\mathrm{DyMnO}_{3}$ single crystals. J. Phys. Condens. Matter 2009, 21, 096002. [CrossRef] [PubMed]

66. Ivanov, V.Y.; Mukhin, A.A.; Prokhorov, A.S.; Balbashov, A.M.; Iskhakova, L.D. Magnetic properties and phase transitions in hexagonal $\mathrm{DyMnO}_{3}$ single crystals. Phys. Solid State 2006, 48, 1726-1729. [CrossRef]

67. Kimura, T.; Lawes, G.; Goto, T.; Tokura, Y.; Ramirez, A.P. Magnetoelectric phase diagrams of orthorhombic $\mathrm{RMnO}_{3}(\mathrm{R}=\mathrm{Gd}, \mathrm{Tb}$, and Dy). Phys. Rev. B 2005, 71, 224425. [CrossRef]

68. Feyerherm, R.; Dudzik, E.; Aliouane, N.; Argyriou, D.N. Commensurate Dy magnetic ordering associated with incommensurate lattice distortion in multiferroic DyMnO 3 . Phys. Rev. B 2006, 73, 180401(R). [CrossRef]

69. Nandi, S.; Kreyssig, A.; Yan, J.Q.; Vannette, M.D.; Lang, J.C.; Tan, L.; Kim, J.W.; Prozorov, R.; Lagrasso, T.A.; McQueeney, R.J.; et al. Magnetic structure of $\mathrm{Dy}^{3+}$ in hexagonal multiferroic DyMnO 3 . Phys. Rev. B 2008, 78, 075118. [CrossRef]

70. Kimura, T.; Tokura, Y. Magnetoelectric phase control in a magnetic system showing cycloidal/conical spin order. J. Phys. Condens. Matter 2008, 20, 434204. [CrossRef]

71. Wehrenfennig, C.; Meier, D.; Lottermoser, T.; Lonkai, T.; Hoffmann, J.U.; Aliouane, N.; Argyriou, D.N.; Fiebig, M. Incompatible magnetic order in multiferroic hexagonal DyMnO3. Phys. Rev. B 2010, 82, 100414 (R). [CrossRef] 
72. Pękała, M.; Wolff-Fabris, F.; Fagnard, J.F.; Vanderbemden, P.; Mucha, J.; Gospodinov, M.M.; Lovchinov, V.; Ausloos, M. Magnetic properties and anisotropy of orthorhombic $\mathrm{DyMnO}_{3}$ single crystal. J. Magn. Magn. Mater. 2013, 335, 46-52. [CrossRef]

73. Sari, O.; Balli, M.; Trottet, G.; Bonhote, P.; Egolf, P.W.; Muller, C.; Heitzler, J.C.; Bour, S. Initial results of a test-bed magnetic refrigeration machine with practical running conditions. In Proceedings of the 3rd International Conference on Magnetic Refrigeration at Room Temperature, Des Moines, IA, USA, 2009; pp. 371-380.

74. Lorenz, B.; Yen, F.; Gospodinov, M.M.; Chu, C.W. Field-induced phases in $\mathrm{HoMnO}_{3}$ at low temperatures. Phys. Rev. B 2005, 71, 014438. [CrossRef]

75. Midya, A.; Mandal, P.; Das, S.; Banerjee, S.; Chandra, L.S.; Ganesan, V.; Barman, S.R. Magnetocaloric effect in $\mathrm{HoMnO}_{3}$ crystal. Appl. Phys. Lett. 2010, 96, 142514. [CrossRef]

76. Munoz, A.; Alonso, J.A.; Martínez-Lope, M.J.; Casáis, M.T.; Martínez, J.L.; Fernandez-Diaz, M.T. Evolution of the magnetic structure of hexagonal $\mathrm{HoMnO}_{3}$ from neutron powder diffraction data. Chem. Mater. 2001, 13, 1497-1505. [CrossRef]

77. Fiebig, M.; Lottermoser, T.; Pisarev, R.V. Spin-rotation phenomena and magnetic phase diagrams of hexagonal $\mathrm{RMnO}_{3}$. J. Appl. Phys. 2003, 93, 8194-8196. [CrossRef]

78. Lonkai, T.; Hohlwein, D.; Ihringer, J.; Prandl, W. The magnetic structures of $\mathrm{YMnO}_{3}-\delta$ and $\mathrm{HoMnO}_{3}$. Appl. Phys. A Mater. Sci. Process 2002, 74, s843-s845. [CrossRef]

79. Hur, N.; Jeong, I.K.; Hundley, M.F.; Kim, S.B.; Cheong, S.W. Giant magnetoelectric effect in multiferroic $\mathrm{HoMnO}_{3}$ with a high ferroelectric transition temperature. Phys. Rev. B 2009, 79, 134120. [CrossRef]

80. De Lacheisserie, E.D.T. Magnétisme: Fondements; EDP Sciences: Les Ulis, France, 2000.

81. Kim, J.W.; Nenkov, K.; Schultz, L.; Dörr, K. Magnetic properties of thick multiferroic hexagonal $\mathrm{HoMnO}_{3}$ films. J. Magn. Magn. Mater. 2009, 321, 1727-1730. [CrossRef]

82. Wilkins, S.B.; Forrest, T.R.; Beale, T.A.W.; Bland, S.R.; Walker, H.C.; Mannix, D.; Yakhou, F.; Prabhakaran, D.; Boothroyd, A.T.; Hill, J.P.; et al. Nature of the Magnetic Order and Origin of Induced Ferroelectricity in $\mathrm{TbMnO}_{3}$. Phys. Rev. Lett. 2009, 103, 207602. [CrossRef] [PubMed]

83. Kajimoto, R.; Yoshizawa, H.; Shintani, H.; Kimura, T.; Tokura, Y. Magnetic structure of $\mathrm{TbMnO}_{3}$ by neutron diffraction. Phys. Rev. B 2004, 70, 012401. [CrossRef]

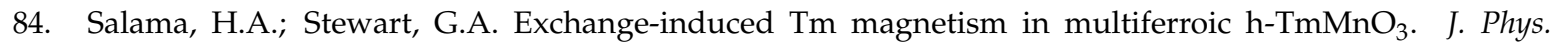
Condens. Matter 2009, 21, 386001. [CrossRef] [PubMed]

85. Yen, F.; Dela Cruz, C.; Lorenz, B.; Galstyan, E.; Sun, Y.Y.; Gospodinov, M.; Chu, C.W. Magnetic phase diagrams of multiferroic hexagonal $\mathrm{RMnO}_{3}(\mathrm{R}=\mathrm{Er}, \mathrm{Yb}, \mathrm{Tm}$, and Ho). J. Mater. Res. 2007, 22, 2163-2173. [CrossRef]

86. Fabreges, X.; Mirebeau, I.; Bonville, P.; Petit, S.; Lebras-Jasmin, G.; Forget, A.; André, G.; Pailhes, S. Magnetic order in $\mathrm{YbMnO}_{3}$ studied by neutron diffraction and Mössbauer spectroscopy. Phys. Rev. B 2008, 78, 214422. [CrossRef]

87. Wagh, A.A.; Suresh, K.G.; Kumar, P.A.; Elizabeth, S. Low temperature giant magnetocaloric effect in multiferroic $\mathrm{GdMnO}_{3}$ single crystals. J. Phys. D 2015, 48, 135001. [CrossRef]

88. Hemberger, J.; Lobina, S.; Von Nidda, H.A.K.; Tristan, N.; Ivanov, V.Y.; Mukhin, A.A.; Balbashov, A.M.; Loidl, A. Complex interplay of 3d and $4 \mathrm{f}$ magnetism in $\mathrm{La}_{1-\mathrm{x}} \mathrm{Gd}_{\mathrm{x}} \mathrm{MnO}_{3}$. Phys. Rev. B 2004, 70, 024414. [CrossRef]

89. Chandra, S.; Biswas, A.; Phan, M.H.; Srikanth, H. Impacts of nanostructuring and magnetic ordering of $\mathrm{Nd}^{3+}$ on themagnetic and magnetocaloric response in $\mathrm{NdMnO}_{3}$. J. Magn. Magn. Mater. 2015, 384, 138-143. [CrossRef]

90. Da Silva, C.A.; Silva, R.S.; Plaza, E.J.R.; Moreno, N.O. Magnetic State and Magnetocaloric Effect of $\mathrm{SmMnO}_{3}$. J. Supercond. Nov. Magn. 2013, 26, 2497-2499. [CrossRef]

91. Sagar, E.; Pavan Kumar, N.; Esakkimuthuraju, M.; Reddy, P.V. Magnetocaloric effect in multiferroic $\mathrm{EuMnO}_{3}$. Phys. Express 2015, 5, 3.

92. Samanta, T.; Das, I.; Banerjee, S. Giant magnetocaloric effect in antiferromagnetic $\mathrm{ErRu}_{2} \mathrm{Si}_{2}$ compound. Appl. Phys. Lett. 2007, 91, 152506. [CrossRef]

93. Midya, A.; Mandal, P.; Rubi, K.; Chen, R.; Wang, J.S.; Mahendiran, R.; Lorusso, G.; Evangelisti, M. Large adiabatic temperature and magnetic entropy changes in $\mathrm{EuTiO}_{3}$. Phy. Rev. B 2016, 93, 094422. [CrossRef] 
94. Mo, Z.J.; Hao, Z.H.; Shen, J.; Li, L.; Wu, J.F.; Hu, F.X.; Sun, J.R.; Shen, B.G. Observation of giant magnetocaloric effect in $\mathrm{EuTi}_{1-\mathrm{x}} \mathrm{Cr}_{\mathrm{x}} \mathrm{O}_{3}$. J. Alloys Compd. 2015, 649, 674-678. [CrossRef]

95. Von Ranke, P.J.; Alho, B.P.; Nóbrega, E.P.; De Sousa, V.S.R.; Alvarenga, T.S.T.; Carvalho, A.M.G.; De Oliveira, N.A. The influence of magnetic and electric coupling properties on the magnetocaloric effect in quantum paraelectric $\mathrm{EuTiO}_{3}$. J. Magn. Magn. Mater. 2012, 324, 1290-1295. [CrossRef]

96. Ke, Y.J.; Zhang, X.Q.; Ma, Y.; Cheng, Z.H. Anisotropic magnetic entropy change in $\mathrm{RFeO}_{3}$ single crystals $(\mathrm{R}=$ Tb, Tm, or Y). Sci. Rep. 2016, 6, 19775. [CrossRef] [PubMed]

97. Arrott, A.; Noakes, J.E. Approximate equation of state for nickel near its critical temperature. Phys. Rev. Lett. 1967, 19, 786. [CrossRef]

98. Hu, W.J.; Du, J.; Li, B.; Zhang, Q.; Zhang, Z.D. Giant magnetocaloric effect in the Ising antiferromagnet DySb. Appl. Phys. Lett. 2008, 92, 192505. [CrossRef]

99. Li, L.; Nishimura, K.; Hutchison, W.D.; Qian, Z.; Huo, D.; NamiKi, T. Giant reversible magnetocaloric effect in $\mathrm{ErMn}_{2} \mathrm{Si}_{2}$ compound with a second order magnetic phase transition. Appl. Phys. Lett. 2012, 100, 152403. [CrossRef]

100. Balli, M.; Jandl, S.; Fournier, P.; Dimitrov, D.Z. On the conventional and rotating magnetocaloric effects in multiferroic $\mathrm{TbMn}_{2} \mathrm{O}_{5}$ single crystals. arXiv 2016.

(C) 2017 by the authors; licensee MDPI, Basel, Switzerland. This article is an open access article distributed under the terms and conditions of the Creative Commons Attribution (CC BY) license (http:/ / creativecommons.org/licenses/by/4.0/). 